PNL-3238

UC-83

\title{
Neutronic Experiment Planning for the Fuels Refabrication and Development Program
}

B. F. Gore

J. P. McNeese

M. G. Zimmerman

G. J. Konzek

December 1979

Prepared for the U.S. Department of Energy under Contract EY-76-C-06-1830

Pacific Northwest Laboratory Operated for the U.S. Department of Energy by Battelle Memorial Institute 


\title{
NOTICE
}

This report was prepared as an account of work sponsored by the United States Government. Neither the United States nor the Department of Energy, nor any of their employees, nor any of their contractors, subcontractors, or their employees, makes any warranty, express or implied, or assumes any legal liability or responsibility for the accuracy, completeness or usefulness of any information, apparatus, product or process disclosed, or represents that its use would not infringe privately owned rights.

The views, opinions and conclusions contained in this report are those of the contractor and do not necessarily represent those of the United States Government or the United States Department of Energy.

\author{
PACIFIC NORTHWEST LABORATORY \\ operated by \\ BATTELLE \\ for the \\ UNITED STATES DEPARTMENT OF ENERCY \\ Under Contract EY-76-C-06-1830
}

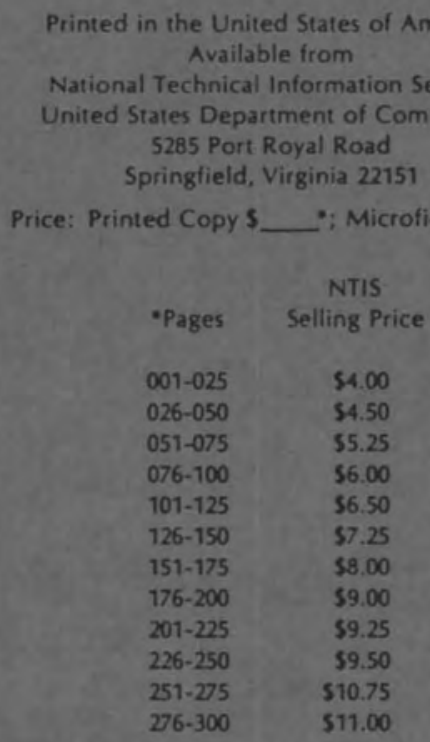




\section{NEUTRONIC EXPERIMENT PLANNING FOR THE FUELS} REFABRICATION AND DEVELOPMENT PROGRAM
B. F. Gore
J. P. McNeese
M. G. Zimmerman
G. J. Konzek

December 1979

Prepared for the U.S. Department of Energy under Contract EY-76-C-06-1830

Pacific Northwest Laboratory Operated for the U.S. Department of Energy by Battelle Memorial Institute 


\section{ACKNOWLEDGEMENTS}

Evaluations of facility capabilities and estimates of costs of required modification and experimentation were prepared by George Konzek for the PRCF and by Ray Lloyd for the CML. Their contributions are greatly appreciated.

Our contacts at BAPL, Ken Richardson and Ray Davis, were most responsive to our incessant questions and suggestions. We were able to establish a very effective, highly informal relationship which was most cordial. We look forward to working with them again, should the occasion arise. 


\section{SUMMARY}

A program of experiments using ${ }^{233} \mathrm{UO}_{2}$ - $\mathrm{ThO}_{2}$ fuel was proposed to provide new and improved neutronic and criticality data for thorium based nuclear fuels. The experiments would provide data to support the licensing of ${ }^{233} \mathrm{UO}_{2}-\mathrm{ThO}_{2}$ fuels in light water reactor cores. This would support the goal of the Fuels Refabrication and Development (FRAD) Program to develop technology for proliferation resistant fuel cycles to a point where fuel cycle choice is not limited by refabrication technology. The proposed program was funded at a low level, with directions that it be planned and performed over a several year time span.

The proposed experimental program is described in this document, along with initial planning and fuel acquisition activities undertaken during FY 1979. Termination activities undertaken during the fourth quarter of FY 1979 are also described. The program was terminated following notification that the DOEsponsored denatured LWR Fuel Program which the experiments supported was to be discontinued.

During FY 1980 the initial experiments were to be performed using uniform cylindrical lattices. These experiments would determine the parameters of critical lattices, providing data useful for validation of computer codes used for criticality safety analyses. These experiments would be followed in subsequent years by experiments using non-uniform lattices which would provide data on the reactivity worths of fuel and control rods, water channels and structural materials. A central feature of these later experiments would be direct determination of power profiles in critical lattices by measurements of gamma activities resulting from fissions in the fuel rods.

The choice of fuel for experimentation was restricted by funding limitations to rods already fabricated under other programs. Only one batch of fuel rods was available, containing 896 rods of $3 \% \mathrm{UO}_{2}-\mathrm{ThO}_{2}$ fuel. The rods are about 4 feet long by $1 / 2$ in diameter, filled with packed particle fuel. The size, enrichment and diameter are quite appropriate for studies of LWR fuels.

The Plutonium Recycle Critical Facility (PRCF) had been used in previous experimental programs which included gamma-scanning measurements. Although 
presently shut down, it was equipped for these measurements. Reactivation of the PRCF was considered and ultimately rejected in favor of experimentation at the operating Critical Mass Laboratory (CML), despite expected disruption of ongoing programs caused by radiation fields emanating from the fuel elements (hard gammas emitted from ${ }^{232} U$ impurity decay daughters).

Estimates were made of shielding required to keep the exposures of CML personnel as low as would be practical. Source terms due to decay of the $24 \mathrm{ppm}{ }^{232} \mathrm{U}$ impurity in the fuel were calculated. These were used to calculate radioactivity dose rates to be encountered during experimentation and fuel rod storage. For a close packed array of rods stored five rows deep, six inches of $\mathrm{Pb}$ placed in front of the array was found to reduce the transmitted dose to $2 \mathrm{mR} / \mathrm{hr}$. Backscatter of gammas from the ceiling was conservatively evaluated and found to yield a somewhat higher dose rate. Consequently six inches of $\mathrm{Pb}$ brick shielding was planned for rod storage arrays.

A dose rate of $23 \mathrm{mR} / \mathrm{hr}$ was calculated at the side of a conservative model of a large experimental lattice in a water-filled tank. Due to the conservatism of the model and the reasonably low dose rate no shielding was planned for the sides of the existing experimental tank.

A dose rate exceeding $100 \mathrm{mR} / \mathrm{hr}$ was calculated above a model of a large lattice covered by one foot of water. Plans were therefore made to provide shielding equivalent to two inches of lead for personnel loading lattices from above the tank. This would reduce the dose rate by a factor of about ten.

The fuel rods requested for experimentation had previously been used in a series of subcritical exponential experiments which provide the only existing source of criticality data for uniform lattices of ${ }^{233} \mathrm{UO}_{2}$ - $\mathrm{ThO}_{2}$ rods. For initial experiments it was planned to perform critical approach experiments on lattices of minimum size and on lattices requiring a minimum number of fuel rods. Experiments were also planned at low moderator-to-fuel (M/F) volume ratios, where discrepancies between calculations and experiments are often found. In particular, an experiment was planned at the lowest M/F ratio for which criticality could be achieved with reasonable certainty using the 896 existing fuel rods. 
Estimates of critical lattice size adequate for experiment planning were obtained from the published results of the exponential experiments previously performed with these rods over the range of $M / F$ ratios from 1.0 to 6.8 . Extrapolation of these results indicated that an experiment at $M / F=0.8$ might be possible, but the extrapolation was highly uncertain. Calculations were performed and tested by predicting critical lattice sizes for lattices studied in the exponential experiments. From these results a conservative calculational bias was established and used to adjust the calculational results. It was finally concluded that a lattice having $M / F=0.8$ should be critical or supercritical if it contained 829 rods. An experiment having this M/F ratio was therefore planned since such a lattice is acceptably close to using all rods, yet it leaves a small contingency should the bias estimate be low.

Results of neutron balance calculations for the subcritical exponential lattices (used to estimate calculational bias) exhibit scatter at low M/F ratios. Calculations by others of these experiments yield scattered results displaced in the same directions from a smooth curve drawn through the calculated points. It was hoped that the critical experiments planned would help determine whether this scatter is an artifact of the calculational methods or whether it results from the experiments themselves. Because the planned experiments were cancelled this question was not answered.

At the time when planning for the experiments was cancelled, shipping containers had been fabricated and purchased to ship the fuel rods to PNL from Bettis Atomic Power Laboratory (BAPL) where they were stored. Due to a combination of shielding and weight requirements a maximum of twelve rods could be shipped per 100 gallon drum (DOT specification 6M). A series of shipments in late FY 1979 and FY 1980 was planned. The PNL request for the fuel rods was withdrawn when experiment planning was cancelled. The shipping containers will now be used by BAPL to ship the rods to the Idaho Transuranic Storage Area. 
.

, 


\section{CONTENTS}

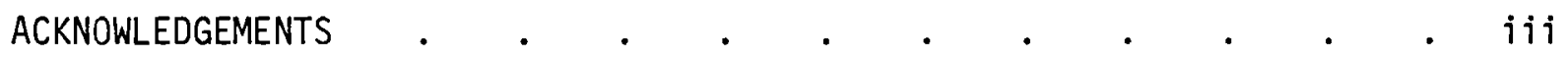

I. SUMMARY

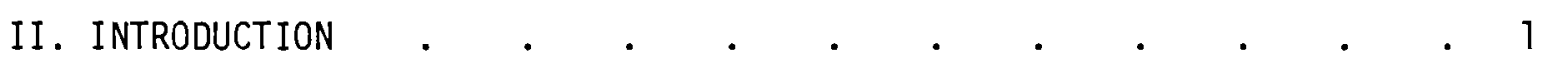

III. NEED FOR ${ }^{233} \mathrm{UO}_{2}-\mathrm{THO}_{2}$ NEUTRONICS DATA $\quad . \quad . \quad . \quad . \quad . \quad . \quad . \quad 3$

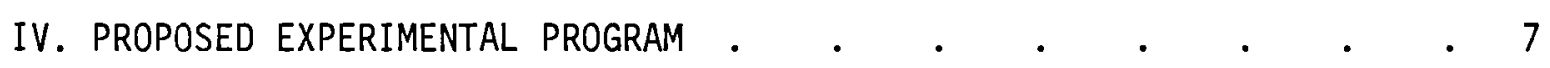

V. FACILITY EVALUATION AND SELECTION

VI. DOSE CALCULATIONS AND SHIELDING REQUIREMENTS • • • • • • • 15

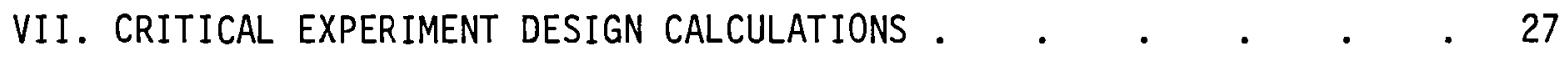

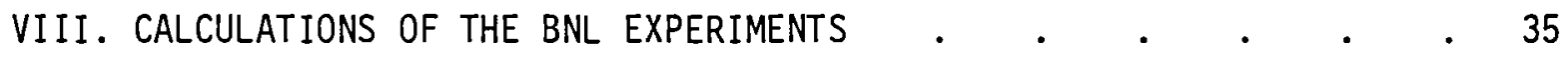

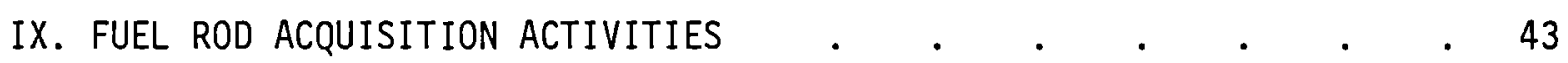

APPENDIX: DESIGN REQUIREMENTS FOR SHIELDED CONTAINERS FOR SHIPMENT OF KILORODS .

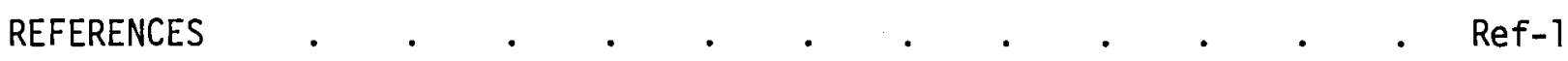




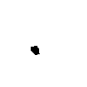




\section{FIGURES}

FIGURE 1. Proposed Milestones for Neutronics and Criticality Experiments Funded at $\$ 200 \mathrm{~K}$ Per Year . . . . . 10

FIGURE 2. Calculational Model for Fuel Storage Array . . . . 19

FIGURE 3. Dose Rate from Rod Storage Array as a Function of Shielding Thickness

FIGURE 4. Tank for Lattice Experiments . . . . . . . . 22

FIGURE 5. Dose Rate as a Function of Shield Thickness Beside a Cylindrical Tank . . . . . . . . . . . 23

FIGURE 6. ${ }^{233} U$ fuel Rod . . . . . . . . . 24

FIGURE 7. Calculational Model for the Top of the Water Filled Tank . 25

FIGURE 8. Dose Rate on Top of Tank as a Function of Water Thickness . 26

FIGURE 9. Buckling Valves Measured in the BNL Experiments . . . 29

FIGURE 10. Reflector Savings Measured in the BNL Experiments . . 30

FIGURE 11. Number of Rods Required for Criticality . . . . 32

FIGURE 12. Keff Values Calculated (Including Axial Neutron Leakage) for the BNL Experiments, Plus Bias Estimate. . . . 38

FIGURE 13. BAPL Calculated Values of $k_{\text {eff }}$ for the BNL Experiments . 41

\section{$\underline{\text { TABLES }}$}

TABLE 1. ${ }^{233} \mathrm{UO}_{2}-\mathrm{ThO}_{2}$ Fuel Pin Composition (Reference 6) . . . 16

TABLE 2. Gamma Yields and Spectrum Calculated per Gram of ThO $\mathrm{T}_{2}$ After 15 Years of Radioactive Decay . . . . . . . 17

TABLE 3. Calculated Dose Rates from a Single Rod . . . . . 18

TABLE 4. Buckling and Reflected Extrapolation Length for Unpoisoned ${ }^{233} \mathrm{UO}_{2}-\mathrm{ThO}_{2}-\mathrm{H}_{2} \mathrm{O}$ Lattices (Reference 6) . . . . . 28

TABLE 5. Predicted Number of Rods Required for Criticality . . . 33

TABLE 6. Lattice Parameters of BNL Exponential Experiments Calculated 37

TABLE 7. Values of $k$ eff Calculated for the BNL Experiments. Also Values from the Bias Estimated of Figure 12 . . . . 39 


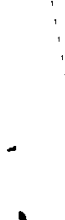

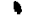




\section{INTRODUCTION}

This report describes activities carried out during FY 1979 at PNL's Critical Mass Laboratory in support of the Fuels Refabrication and Development (FRAD) Program. The FRAD program was focused on developing the technology base for proliferation resistant fuels, including alternatives to uranium $\left(\mathrm{UO}_{2}\right)$ and plutonium recycle $\left(\mathrm{UO}_{2}-\mathrm{PuO}_{2}\right)$ fuels. In support of $\mathrm{FRAD}$ program objectives an experimental program was proposed and initiated to provide new and improved data useful in the fields of neutronic and criticality analysis for thorium-based fuels.

This experimental program was undertaken to provide needed data for validation of core design analyses having sufficient quality and depth to support the 1 icensing of ${ }^{233} \mathrm{UO}_{2}-\mathrm{ThO}_{2}$ fuels for use in LWR cores. The need for this data is discussed in Section 3 of this document and in Reference 1 which was published separately as part of the program described herein.

The proposed experimental program is described in Section 4. This program was authorized and initiated to the extent of arranging for acquisition of fuel rods, evaluation and selection of experimental facility (Section 5), prediction of radiation dose rates during experimentation as a function of shielding thickness (Section 6), and calculations supporting experiment design (Section 7). Planning for fuel rod acquisition is described in Section 8 .

However, in late FY 1979 the DOE program for development of denatured LWR fuel was cancelled. Since this program provided the interest in and need for data to be produced by the proposed experimental program, the experiments were also cancelled. This document reports activities carried out prior to program termination. 
. 


\section{I. NEED FOR ${ }^{233} \mathrm{UO}_{2}-\mathrm{THO}_{2}$ NEUTRONICS DATA}

Criticality data involving thorium or ${ }^{233} U$ and light water moderator have been compiled ${ }^{(2)}$ in support of an earlier program, the Thorium Fuel Cycle Technology (TFCT) Program. Review of these data indicates that the only critical lattices of ${ }^{233} \mathrm{UO}_{2}-\mathrm{ThO}_{2}$ fuel rods ever measured were "seed and blanket" cores assembled for the LWBR program. $(3,4)$ These experiments were characterized by radial zoning of both fuel rod size and ${ }^{233} \mathrm{U}$ enrichment. In these experiments a fissile "seed" region of smaller rods ( 0.25 to 0.31 in. diameter) was surrounded by a fertile blanket region of larger rods ( 0.53 to 0.63 in. diameter) containing little or no fissile ${ }^{233} \mathrm{U}$.

In addition to the radial zoning of the LWBR seed and blanket critical cores, axial zoning was also employed. In all but one of these lattices fissile enrichment in the seed and/or blanket regions was additionally varied in the axial direction. In some cases multiple seed and blanket regions were used. The complexity of these lattices makes them of extremely limited usefulness as benchmark experiments for validation of calculational methods. Adequate neutronic analysis of these cores requires multi-dimensional Monte Carlo calculations. Although neutronic parameters such as epithermal-to-thermal capture and fission ratios were measured in these experiments, a recent review of thorium $233 \mathrm{U}$ thermal reactor benchmark studies notes that, "It is judged that analysis of the measured parameters is not likely to be fruitful for cross section testing purposes mainly because of the complexity of these cores, and no attempt has been made to calculate them." ${ }^{(5)}$

The only other experiments giving criticality information of significance for light water moderated ${ }^{233} U$ - Thorium systems were a series of subcritical exponential lattice measurements. ${ }^{(6)}$ Despite the fact that these lattices were not brought critical, measurements of material buckling, flux relaxation length and reflector savings were made. These are the only existing criticality benchmark experiments using single-diameter, single-enrichment rods of ${ }^{233} \mathrm{UO}_{2}-\mathrm{ThO}_{2}$ fuel.

All existing integral neutronics data for ${ }^{233} U$-Th systems were produced in the two programs identified above. A review of those data was published as part 
of this (FRAD) program under separate cover. (1) Compilation of data for that document had begun previously under the auspices of the Thorium Fuel Cycle Technology (TFCT) program which was terminated at the end of FY 1978. Table 1 of Reference 1 summarizes the neutronics parameters measured for each of the experimental programs. Additional data applicable to light water moderated systems are also identified for experimental programs investigating ${ }^{235} \mathrm{UO}_{2}$ $\mathrm{ThO}_{2}$ lattices and homogeneous solutions of ${ }^{233} \mathrm{U}$ in the absence of thorium. The result of the review reported in Reference 1 is: "It is concluded that insufficient data are currently available to validate neutronics design methods for licensing the ${ }^{233} \mathrm{UO}_{2}$ - $\mathrm{ThO}_{2}$ fuel cycle in light water reactors." This conclusion is in agreement with conclusions reached by researchers who have compared calculations using standard reactor design analysis techniques to experimental results. (7)

Data needed for the validation of design analysis calculational tools include the critical configurations of fuel rods having uniform size and enrichment assembled in uniform cylindrical lattices which are completely immersed, with control and safety rods completely withdrawn. These data would supplement the results of Reference 6 and help remove some of the questions arising from attempts to calculate these experiments (discussed in Section 6 of this document). Such data would also be valuable for determining bias in the results of calculational codes used for the criticality safety analysis of nuclear fuel cycle facilities.

In addition, critical lattice data from non-uniform lattices of a single fuel pin type are needed. Experiments in which water channels, structural material, and control rods are included would allow verification of calculations of the reactivity worths of these materials. Also needed are measurements to verify the reactivity worths of peripheral fuel rods in uniform lattices. The effects of dissolved boron on the criticality of uniform lattices need to be determined, although the experiments of Reference 6 provide some data. However, the reactivity worth of incremental boron additions needs to be measured. 
Finally, power distribution profiles throughout uniform critical lattices need to be measured to verify calculational predictions. To avoid flux perturbation problems associated with the use of activation and fission foils for these measurements, a technique has been developed in which the fission product contents of rods from low-power critical cores are measured directly. Power profiles are obtained by scanning the intensity of fission product gamma emissions. (8) These measurements are needed for confirmation of design analysis tools used to determine arrangements of fuel rods and burnable poison rods, plus fissile enrichment gradations, which will minimize power peaking effects and thereby enhance the efficiency and safety of reactor operation.

This document describes the initial steps in an experimental program addressed to meeting these needs. 


\section{PROPOSED EXPERIMENTAL PROGRAM}

Discussions of programmatic needs and timing resulted in a proposed experimental program of modest scope and expense. The technology-development objectives of the FRAD program were of such breadth that a major effort directed toward provision of basic neutronics data for a single fuel cycle was not considered appropriate. The FRAD program schedule indicated need for data from supporting studies by the mid 1980's. Consequently, a several-year, low-level program was proposed.

While reviewing existing neutronics data from ${ }^{233} \mathrm{UO}_{2}-\mathrm{ThO}_{2}$ experiments it was noted that no data from critical, uniform lattices of single type fuel rods existed. Such data would be valuable to criticality safety analyses used for setting material and process limits in fuel cycle activities such as fuel fabrication. Data from subcritical exponential experiments were available, but such data make it difficult to assess the bias in calculated values of effective neutron multiplication, $k_{\text {eff }}$, because the critical condition is imprecisely defined. The importance of determining calculational bias is indicated by the following quotation from the American National Standard ANSI-N16.9-1975, "Bias shall be established by correlating the results of criticality experiments with results obtained for those same systems by the method being validated. Commonly the correlation is expressed in terms of the values of effective neutron multiplication factor calculated for the experimenta 1 systems, but other parameters may be used." "The uncertainty in the bias shall contain allowances for uncertainties in the experimental conditions, for lack of precision in the calculational method, and for extension of the area(s) of applicability. When adequate allowance is made for the uncertainty in the bias, conditions predicted to be subcritical would be expected to be subcritical."

In recognition of a need for experiments to provide data useful for criticality safety analyses, as well as integral neutronics data, it was decided that the proposed program would start with a series of straightforward, uniform lattice critical benchmark experiments. It would then progress to more complex geometrical arrangements and more sophisticated measurement techniques as a second phase. 
A major decision in planning a program of lattice experiments is choice of the source of fuel rods to be used. Specially fabricated fuel rods can cost more than $\$ 1,000$ apiece, with hundreds required for critical lattices of lowenriched fuel in water moderator. Also, acquisition of fuel materials and rod fabrication can be quite time consuming. Finally, ${ }^{233} \mathrm{U}$ is always contaminated to some extent with ${ }^{232} \mathrm{U}$ which is produced as an unwanted byproduct in the transmutation of thorium to uranium. The radioactive decay of ${ }^{232} U$ yields a chain of radioactive daughter products including ${ }^{208} \mathrm{Tl}$, which emits a $2.6 \mathrm{MeV}$ gamma ray. Consequently, ${ }^{233} \mathrm{U}$ fuels emit penetrating hard gamma radiation which complicates fabrication and handling. Therefore, fabrication of special fuel was considered beyond the scope appropriate for a modest experimental program.

Inquiries yielded the information that only one batch of identical ${ }^{233} \mathrm{UO}_{2}$ $\mathrm{ThO}_{2}$ fuel rods containing sufficient rods for critical experiments was available. This batch consisted of 896 rods of $3 \%{ }^{233} \mathrm{UO}_{2}-\mathrm{ThO}_{2}$ compacted particle fuel. The rods were $1 / 2$ inch in diameter $\times 4$ feet long, clad with Zircalloy-2' tubing. The fuel had been produced via the sol-gel process in the Kilorod facility at ORNL. ${ }^{(9)}$ This process yields fuel particles which are a true solid solution of $\mathrm{UO}_{2}$ in $\mathrm{ThO}_{2}$, as would be found in pellet fuel also. The density of the compacted particle fuel was slightly greater than $90 \%$ of theoretical, which is comparable to the average density of pellet fuel inside fuel rods (including gaps between pellets and clad, and between pellets). Consequently neutronic effects in these rods would be directly applicable to rods containing pellet fuel. Furthermore, the rod size and fissile enrichment was appropriate for LWR application. Finally, the 896 identical rods were available as approved excess property and could be obtained for only the cost of packing and shipping.

The available ${ }^{233} \mathrm{UO}_{2}-\mathrm{ThO}_{2}$ fuel rods were those which had originally been used at BNL in subcritical exponential experiments. ${ }^{(6)}$ Published analyses of the exponential experiments yielded reflector savings values differing by several percent when different analyses were used. The results from "variable loading" analyses and "flux shape" analyses $(10,11)$ were never reconciled, 
even when corrections for nonasymptotic flux behavior derived from calculations were applied."(11) Eventually "best" values were obtained $(11,6)$ by an averaging process. (A calculated curve was fitted through a plot of the corrected experimental values of reflector savings vs. water/fuel ratio, giving equal weighting to the results of both analyses.) Since for subcritical experiments criticality information is primarily obtained from values of material buckling, $B_{m}^{2}$, and since the reflector savings values are required to calculate $B_{m}^{2}$, the performance of clean critical experiments with uniform lattices of these fuel rods over the optimum range of moderation would remove this source of uncertainty in evaluating the accuracy of calculational methods.

The first phase of the proposed two part program called for acquisition of the fuel rods, planning and preparation for critical experiments, and critical experimentation and analysis during the first phase. Planning and preparation for neutronics experiments would be initiated during the latter part of the first phase. Then, in the second phase, neutronics experiments would be carried out and analyzed, followed by disposal of the fuel rods.

At a funding level of $几 \$ 200 \mathrm{~K} /$ year it was estimated that about four and one half years would be required for the proposed program. Milestone targets are shown in Figure 1. 
FIGURE 1. Proposed Milestones for Neutronics and Criticality Experiments Funded at \$200K Per Year

Milestone

\begin{tabular}{lllll}
\multicolumn{5}{c}{ Fiscal } \\
\hline 1979 & 1980 & 1981 & 1982 & 1983 \\
\hline
\end{tabular}

1. Evaluate Facilities; Estimate Costs

2. Acquire Fuel Rods

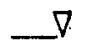

3. Plan and Prepare for Experiments

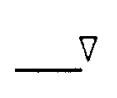

4. Perform Uniform Critical Experiments

5. Analyse and Report Expts.

6. Plan Neutronics Expts

7. Hodify Facility and Equipment

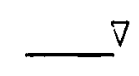

8. Perform Neutronics Experiments

9. Analyze and Report Expts.

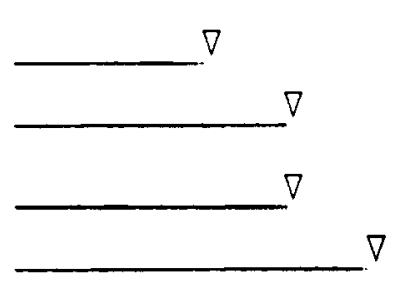

10. Dispose of Fuel Rods 


\section{FACILITY EVALUATION AND SELECTION}

Previous experimental programs have been carried out at PNL to provide benchmark neutronics data to support licensing activities for plutonium recycle fuel. $(8,12,13)$ These programs were carried out in the Plutonium Recycle Critical Facility (PRCF), a low power research reactor having many attractive features for such experiments. In particular, the location of the reactor tank in a separate, below-grade shielded cell allowing high flux operation (to activate fuel rods for gamma-scanning) while minimizing radiation dose to workers is a significant advantage. In addition, gamma scanning electronic equipment, shielding and collimators were in place and operable (they have since been removed to the (ML), and no major structural or facility changes were required for implementation of the proposed program of experiments.

Fuel rods are stored inside the heavily shielded reactor cell at the PRCF. The shielding provided to experimenters and operators by the cell structure would be particularly useful for experimentation using the radioactive ${ }^{233} \mathrm{UO}_{2}-\mathrm{ThO}_{2}$ fuel rods.

However, the PRCF has been in a shutdown standby condition since completion of the previous programs in 1976. Although the operating license for the PRCF is still valid, reactivation of the facility would require extensive maintenance, reinstallation, testing and documentation to achieve operational status. This would be expensive in both dollars and in delay of initiation of critical experimentation. Nevertheless, review of operating requirements indicates that since last operation no additional restrictions have been placed on facility operation or on releases through the ventilating system. Therefore, reactivation would not require extensive facility upgrading. New physical security requirements would require additional intrusion detection and alarm systems, however.

The alternative to experimentation in the PRCF would be the use of PNL's Critical Mass Laboratory (CML). This large modern facility operates routinely to perform critical experiments for various research programs. A major disadvantage of performing gamma-scan experiments at the CML would be the disruption of work on ongoing programs by radiation fields produced by the 
high-flux operation of critical assemblies and by the subsequent handiing and storage of the fuel rods. In fact, considerable additional shielding would be required for operations using the ${ }^{233} \mathrm{UO}_{2}-\mathrm{ThO}_{2}$ fuel prior to irradiation for gamma scanning due to its present radioactivity caused by ${ }^{232} \mathrm{U}$ decay daughters.

To allow the proposed experimental program to proceed in a timely fashion it was decided that initial experiments which did not require the low-power critical irradiation of the fuel for gamma scanning measurements would be carried out at the CML. This would allow the prompt acquisition of fuel elements and initiation of experimentation. This decision removed concerns over timing uncertainties in PRCF reactivation activities and in meeting Operationat Readiness Review requirements.

High flux, low power operation of critical assemblies to achieve fuel irradiation sufficient to allow gamma-scanning measurements is not routinely carried out at the CML. However, critical assemblies are routinely operated at even lower power for flux mapping purposes using solid state particle track recorders and/or foil activation methods. Operation for gamma-scanning measurements would require, in addition to the installation of additional shielding, modification of safety instrumentation. This would be needed to meet the requirements of the CML Technical Specifications (14) that, "At least one safety channel on scale at startup shall remain on scale through attainment of the maximum flux in an operating interval." Nevertheless, it was concluded that, should experimentation in the PRCF prove impractical for any reason, gamma-scan experiments could be carried out at the CML to meet the data needs of the proposed experimental program. With this assurance that the entire experimental program could be performed at the CML if necessary, fuel acquisition was initiated and planning for experimentation was begun.

A review of the activities required to reactivate the PRCF was conducted by the NRC-1icensed Senior Reactor Operator who last operated the PRCF. This was undertaken as part of a study to determine the relative economics of PRCF reactivation versus disruption of ongoing programs by experimentation at the 
CML. The conclusion reached in this review was that reactivation would indeed require a major commitment, but that reactivation should be possible within the schedule requirements of the proposed experimental program.

U1timately, a decision against reactivating the PRCF was made. This decision was based in large part upon perceived uncertainty in DOE fuel cycle study needs over the several-year period required for completion of the experimental program. The soundness of that decision was supported by DOE's termination of the denatured LWR fuel program at the end of FY 1979. 


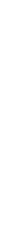




\section{DOSE CALCULATIONS AND SHIELDING REQUIREMENTS}

The ${ }^{233} \mathrm{UO}_{2}-\mathrm{ThO}_{2}$ fuel rods requested for experimentation contain $24 \mathrm{ppm}$ ${ }^{232} \mathrm{U}$ contamination of the ${ }^{233} \mathrm{U}$. The radioactive decay of ${ }^{232} \mathrm{U}$ yields a chain of decay daughters $(15)$ which emit a spectrum of hard gamma radiation extending up to the $2.6 \mathrm{MeV}$ emission of ${ }^{208} \mathrm{Tl}$. Following chemical separation of the uranium the daughter radioactivity "grows in", reaching a maximum in about 10 years after which it decays with the 72 year half-life of ${ }^{232} U$. Since the fuel was produced in the early 1960's, its radioactivity is presently very close to the maximum.

Information on fuel rod radioactivity proved to be difficult to obtain. The rods were stored at Bettis Atomic Power Laboratory (BAPL) where they had previously been used in $D_{2} 0$ - moderated neutronics experiments. ${ }^{(16)}$ BAPL personnel reported that measurements made in 1970, 7 years after fuel separation, indicated that the radiation field of a single rod was $12 \mathrm{mR} / \mathrm{hr}$ at 3 feet and $500 \mathrm{mR} / \mathrm{hr}$ at 1.5 inches from the rod midpoint. They were unwilling to open storage containers to make additional measurements of present radiation fields because it would entail additional radiation exposure of personnel. However, the 1970 measurement results should be representative of present conditions since they were made as rod radioactivity was approaching its maximum value.

Calculations were performed at PNL to determine the gamma source in fifteen year old fuel due to ${ }^{232} U$ and its decay daughters. Gamma yields per gram of fuel and the multi-group gamma spectrum were calculated using the method described in Reference 17. The fuel composition, taken from Reference 6, is given in Table 1, and the results are presented in Table 2. The Targe contribution from the $2.6 \mathrm{MeV}$ gamma from ${ }^{208} \mathrm{Tl}$ is seen in energy group 6 .

The results of the source calculation were then used as input to onedimensional gamma-radiation transport calculations to determine dose rates as a function of location and shielding. The transport code ANISN $(18)$ was used, with multi-group cross sections processed from the Storm-Israel (19) library by the code MUG. ${ }^{(20)}$ Thorium cross sections were not available on 
TABLE 1. ${ }^{233} \mathrm{UO}_{2}-\mathrm{ThO}_{2}$ Fuel Pin Composition (Reference 6)

Average Density $=8.9618 \mathrm{~g} / \mathrm{cm}^{3(a)}$; diameter $=0.430 \mathrm{in} .=1.09220 \mathrm{~cm}$

Actixe Length $=42.5 \mathrm{in},=107.98 \mathrm{~cm}$ $\left({ }^{233} \mathrm{U} t 233 \mathrm{U}+\mathrm{Th}\right)$ wt ratio $=0.03000$

\begin{tabular}{|c|c|c|}
\hline Isotope & Weight Fraction & Atoms $/ \mathrm{cm}^{3}$ \\
\hline $16_{0}$ & 0.121197 & $0.408832 \times 10^{23}$ \\
\hline${ }^{232} \mathrm{Th}$ & 0.851764 & 0.198115 \\
\hline $233 \mathrm{U}$ & 0.026343 & 0.0061021 \\
\hline${ }^{234} U$ & 0.000394 & 0.0000909 \\
\hline${ }^{235} \mathrm{U}$ & 0.000012 & 0.0000027 \\
\hline${ }^{238} U$ & 0.000289 & 0.0000655 \\
\hline B & 0.0000044 & 0.0000220 \\
\hline
\end{tabular}

Clad Composition: Zircaloy-2

$$
\begin{aligned}
& \text { Zircaloy }-2 \\
& \text { density }=6.8365 \mathrm{~g} / \mathrm{cm}^{3} \\
& \text { o.d. }=1.26746 \mathrm{~cm}=0.499 \mathrm{in} . \\
& \text { i.d. }=1.09220 \mathrm{~cm}=0.430 \mathrm{in} .
\end{aligned}
$$

\begin{tabular}{|c|c|c|}
\hline Isotope & Weight Fraction & Atoms $/ \mathrm{cm}^{3}$ \\
\hline $\mathrm{Zr}$ & 0.9827 & $0.44355 \times 10^{23}$ \\
\hline Sn & 0.0145 & 0.005030 \\
\hline $\mathrm{Cr}$ & 0.0010 & 0.000792 \\
\hline $\mathrm{Fe}$ & 0.0013 & 0.000958 \\
\hline $\mathrm{Ni}$ & 0.0005 & 0.000351 \\
\hline Co & $5 \times 10^{-6}$ & 0.0000035 \\
\hline B & $1.4 \times 10^{-6}$ & 0.0000053 \\
\hline $\mathrm{Cd}$ & $0.5 \times 10^{-6}$ & 0.0000002 \\
\hline $\mathrm{Hf}$ & $3 \times 10^{-6}$ & 0.0000007 \\
\hline
\end{tabular}

(a)The fuel was prepared by the sol gel process and consists of compacted particles of a solid solution of $\mathrm{UO}_{2}$ in $\mathrm{ThO}_{2}$. The compacted particles are of three size grades, $60 \mathrm{wt} \% 6 / 16$ mesh, $15 \mathrm{wt} \% 50 / 140$ mesh, and $25 \mathrm{wt} \% 200$ mesh. (1) 
TABLE 2. Garma Yields and Spectrum Calculated per Gram of $\mathrm{ThO}_{2}$ After 15 Years of Radioactive Decay

\begin{tabular}{|c|c|c|}
\hline $\begin{array}{l}\text { Energy } \\
\text { Group }\end{array}$ & $\begin{array}{l}\text { Upper Energy } \\
\text { of Group, Mev }\end{array}$ & $\begin{array}{c}\gamma / \text { sec-gram } \\
\text { Fuel } \\
\end{array}$ \\
\hline 1 & 7.0 & 0.0 \\
\hline 2 & 6.0 & 0.0 \\
\hline 3 & 5.0 & 0.0 \\
\hline 4 & 4.0 & 0.0 \\
\hline 5 & 3.5 & $1.28 \times 10^{-5}$ \\
\hline 6 & 3.0 & $1.67 \times 10^{5}$ \\
\hline 7 & 2.5 & $4.92 \times 10^{-3}$ \\
\hline 8 & 2.0 & $7.92 \times 10^{3}$ \\
\hline 9 & 1.6 & $1.63 \times 10^{3}$ \\
\hline 10 & 1.2 & $4.70 \times 10^{3}$ \\
\hline 11 & 0.9 & $6.22 \times 10^{4}$ \\
\hline 12 & 0.6 & $1.91 \times 10^{5}$ \\
\hline 13 & 0.4 & $2.94 \times 10^{5}$ \\
\hline 14 & 0.21 & $9.70 \times 10^{3}$ \\
\hline 15 & 0.12 & $1.75 \times 10^{5}$ \\
\hline 16 & 0.07 & $3.18 \times 10^{5}$ \\
\hline
\end{tabular}

this library. Therefore, uranium cross sections were used for thorium since they are similar for gamma energies greater than about $100 \mathrm{keV}$.

Dose rates calculated as a function of distance from the midpoint of a single fuel rod are presented in Table 3 . These results contain a hand-calculated adjustment to account for the finite length of the rod which cannot be included in 1-D modeling. Agreement with the 1970 radioactivity measurements is good.

Calculations were then performed to estimate dose rates as a function of shielding thickness for rod storage and for experimental situations. 
TABLE 3. Calculated Dose Rates

from a Single Rod

Jistance from Rod Centerline, $\mathrm{cm}$

Surface

1 foot

1 meter
Dose Rate $\mathrm{R} / \mathrm{hr}$

2.8

0.05

0.01

The results of these calculations provide guidance in determining needs for shielding installation in the critical assembly room.

The calculational model for analyzing the effects of fuel rod storage is shown in Figure 2. The fuel storage lattice was assumed to be a hexagonal close-packed lattice 5 rows deep, which was modeled as a uniform homogenized fuel layer for the 1-D calculation. This would allow storage of the 896 fuel rods in a rack a little longer than 2 meters. The zircaloy cladding was modeled as a metal slab of the same thickness as the fuel rod cladding. This was followed by a $10 \mathrm{~cm}$ air space, and then by lead shielding. Dose rates calculated at the shield surface are presented in Figure 3 . No asséssment of the decrease of the radiation field with distance from the shield was obtained due to the 1-D nature of the calculation (slabs assumed to be of infinite extent). It is seen in Figure 3 that 6 inches of $\mathrm{Pb}$ decreases the dose rate from $9 \mathrm{R} / \mathrm{hr}$ to about $2 \mathrm{mR} / \mathrm{hr}$. This corresponds to two layers of standard $\mathrm{Pb}$ bricks, one stacked flat-wise and one stacked edge-wise (with appropriate supports to prevent accidental collapse).

Shielding for fuel rod storage consisting of simply a wall with no top cover would be preferred for simplicity of construction and fuel rod handling. Consequently a crude estimate was made of the dose rate in the experimental cell caused by gammas backscattering off an 8 in. thick concrete ceiling. A monte carlo calculation of gamma backscatter as a function of angle by a concrete slab was performed assuming a small plane gamma source oriented parallel to the ceiling. The source had unit strength and the spectrum of Table 2. A conservative estimate of backscatter was obtained by multiplying the maximum 


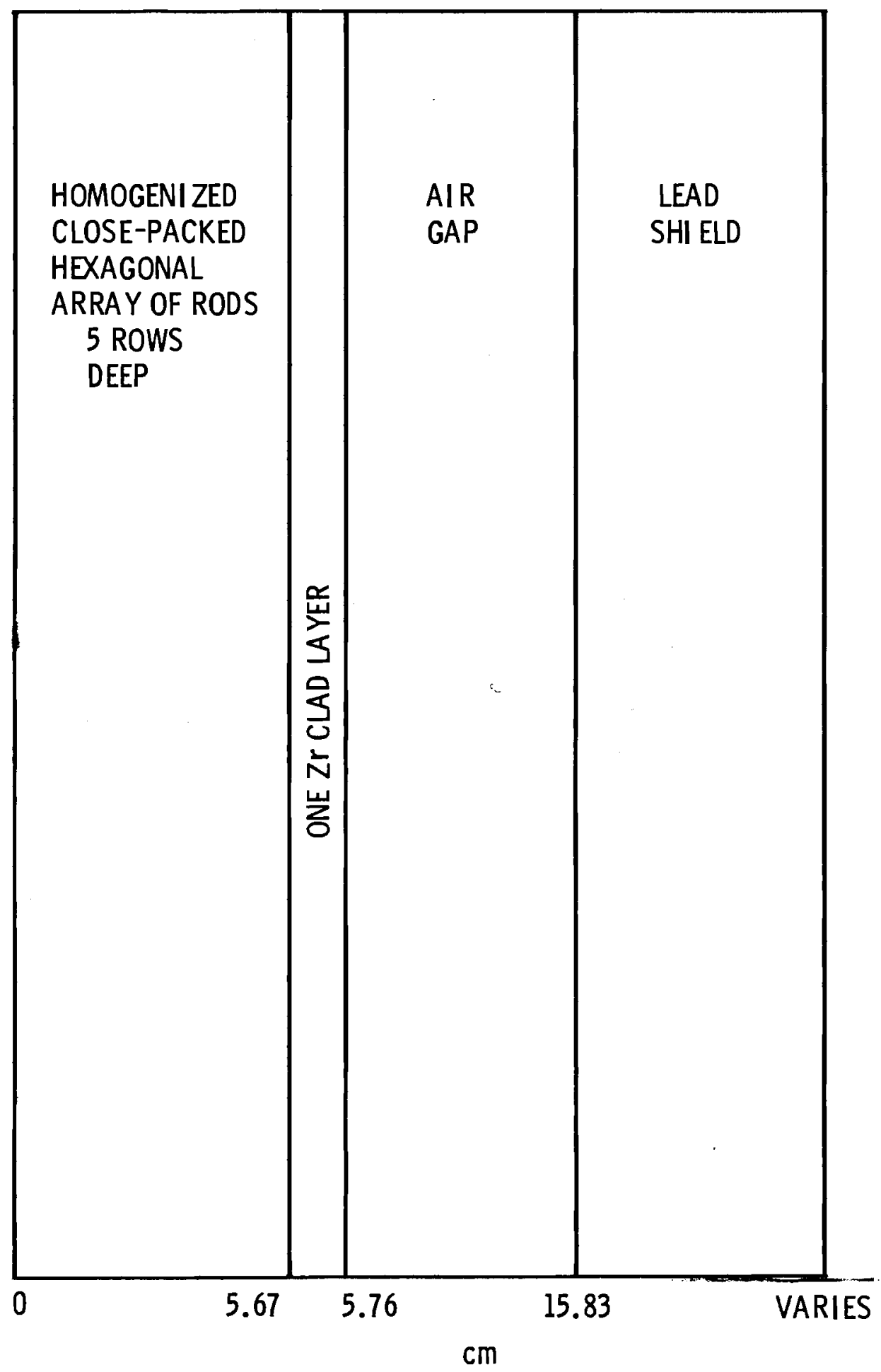

FIGURE 2. Calculational Model for Fuel Storage Array 


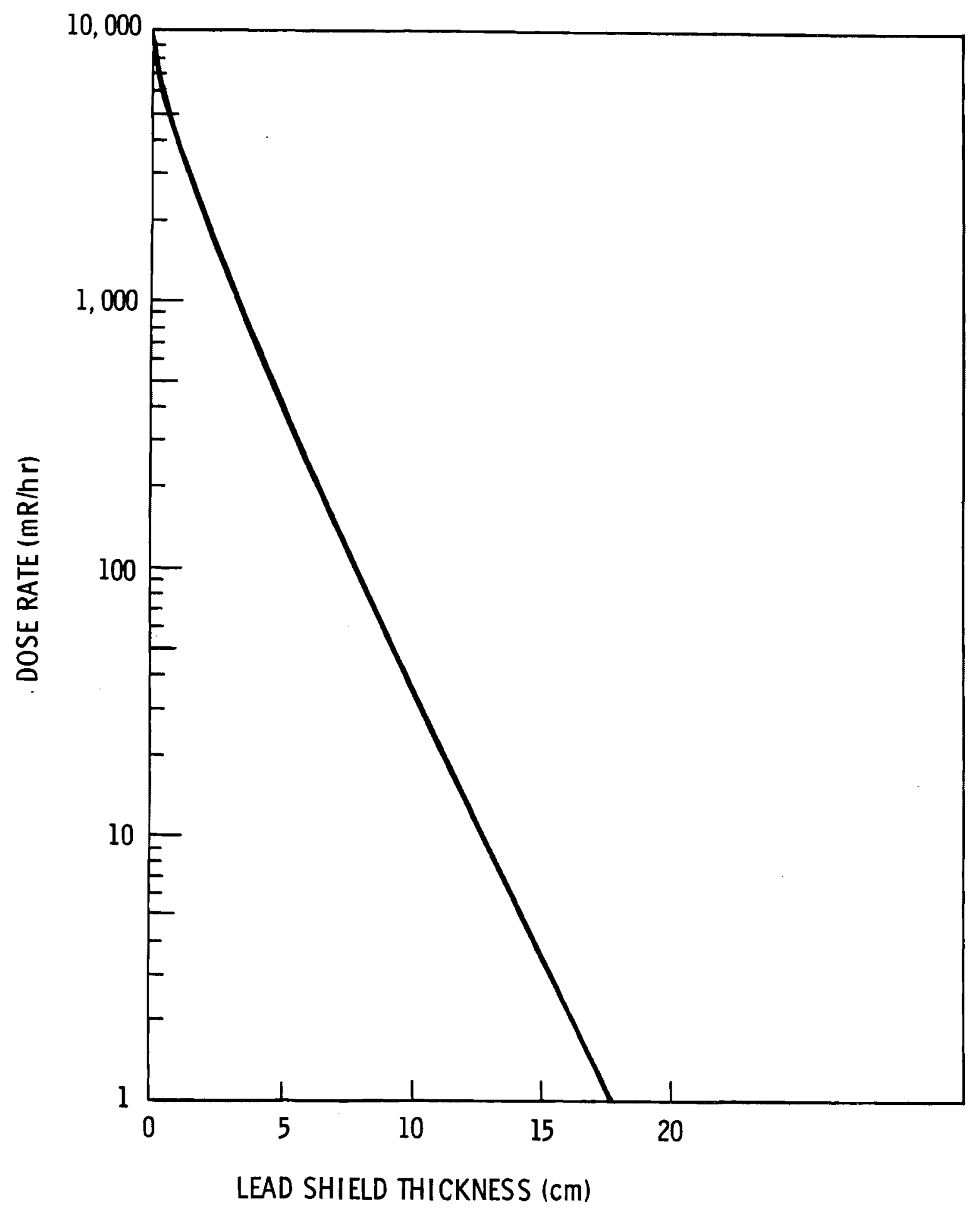

FIGURE 3. Dose Rate from Rod Storage Array as a Function of Shielding Thickness 
backscattered dose rate by the source strength of the unshielded array, times the total area of the top and front face of the array. No credit was taken for the orientation of the front face perpendicular to the ceiling or of possible interception by the shielding wall of radiation emitted by the array. Consequently, the estimate of $18 \mathrm{mR} / \mathrm{hr}$ is believed to be conservative by a factor of several.

On the basis of these estimates shielding for fuel rod storage in the critical assembly room of the CML was planned to be 6 inches thick and of sufficient height to prevent line-of-sight irradiation of personnel involved in experiments. This was expected to hold dose rates from fuel stored in the room to several $\mathrm{mR} / \mathrm{hr}$. Such dose rates would not unduly impede experimentation for other programs following receipt of the rods.

The large tank $(1.8 \mathrm{~m} \times 3 \mathrm{~m} \times 2.1 \mathrm{~m}$ deep) used for critical lattice experiments at the CML is shown in Figure 4. The water inside this tank would provide shielding against much of the radiation emitted by fuel rods in an experimental lattice. An estimate of dose rates to be expected during experimentation was made for a cylindrical lattice of 623 rods having a radius of $40 \mathrm{~cm}$. Such a lattice would be just slightly subcritical. Its water-to-fuel volume ratio would be about 6.8 , considerably more overmoderated than lattices planned for experimentation. Such a large, open lattice was chosen for the estimate to bring the outer fuel rods nearer to the tank sides.

Dose rates transmitted through the tank sides were calculated using the ANISN code. The fuel and water were modeled as a homogeneous mixture in a cylinder of radius $40 \mathrm{~cm}$, which was surrounded by water out to a radius of $90 \mathrm{~cm}$ (tangent to the sides of the actual rectangular tank). Lead shielding was assumed to surround the water reflector, and dose rates were calculated at the shield surface. Calculated dose rates are plotted in Figure 5 as a function of thickness of the $\mathrm{Pb}$ shielding. Calculated dose rates decrease from $23 \mathrm{mR} / \mathrm{hr}$ at the water surface to $2 \mathrm{mR} / \mathrm{hr}$ after 2 inches of $\mathrm{Pb}$ shielding. These dose rates would be reduced by use of tighter lattices, and they are conservative due to the extra water shielding present in the actual rectangular tank. Consequently no shielding was planned for the tank sides. 


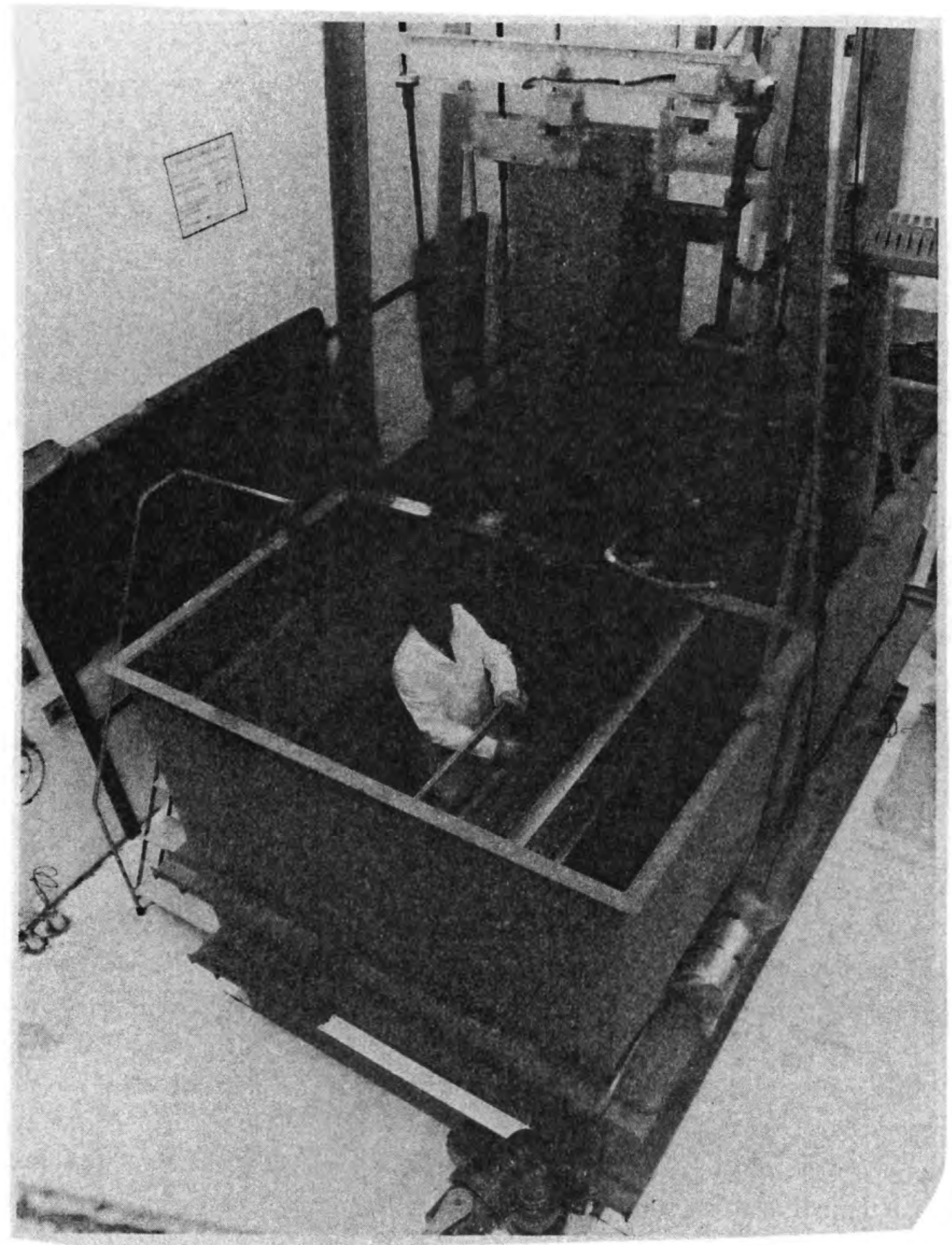

FIGURE 4. Tank for Lattice Experiments 


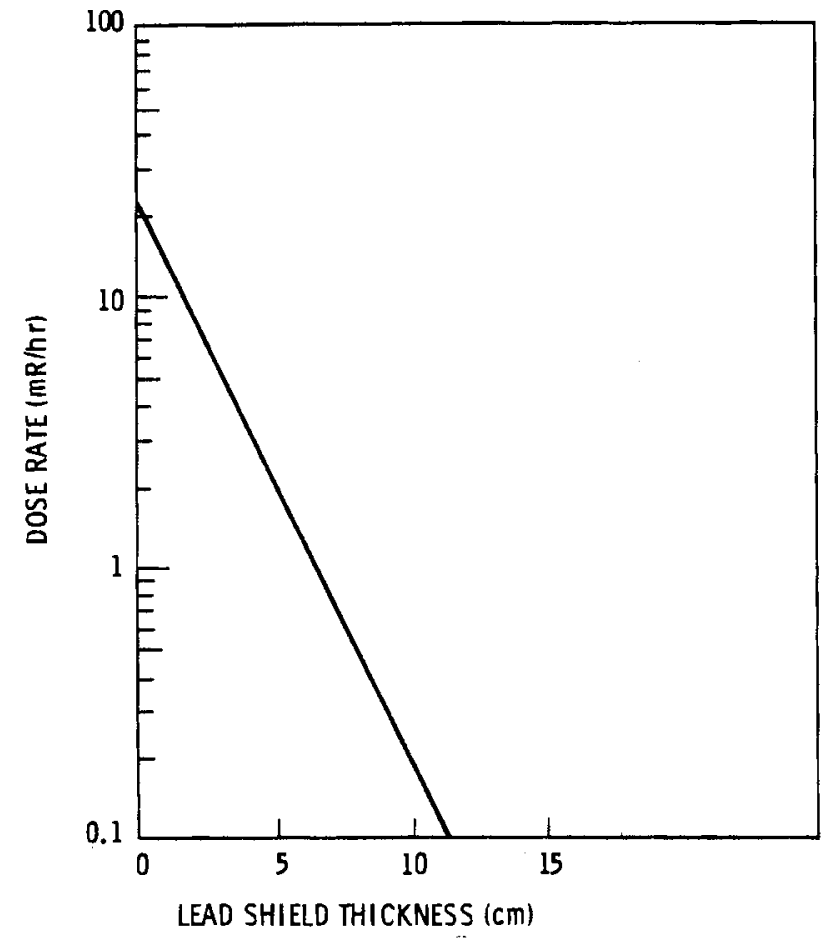

FIGURE 5. Dose Rate as a Function of Shield Thickness Beside a Cylindrical Tank

Dose rates calculated for the region above the tank were found to be considerably higher than those beside the tank. Fuel rod geometry is shown in Figure 6 , and the 1-D slab model used for the calculation is shown in Figure 7. The garma source region is modeled as a homogeneous slab of the water-fuel mixture assumed for the cylindrical calculation reported above. Above the fuel region the model includes homogenized layers of water and fuel rod hardware, plus an air gap to model effects of the plenna located in the rods above the fuel. For calculational simplicity the model is assumed symmetric about the fuel midpoint, since details at the tank bottom will have little or no effect on doses above the tank.

Dose rates calculated on top of the tank are plotted in Figure 8 as a function of water depth over the fuel. The calculated dose rates range from $2 \mathrm{R} / \mathrm{hr}$ when the water ends at the rod tops to $165 \mathrm{mR} / \mathrm{hr}$ when one foot of water covers the rods. Due to the need for a layer of water beneath the rods as a 


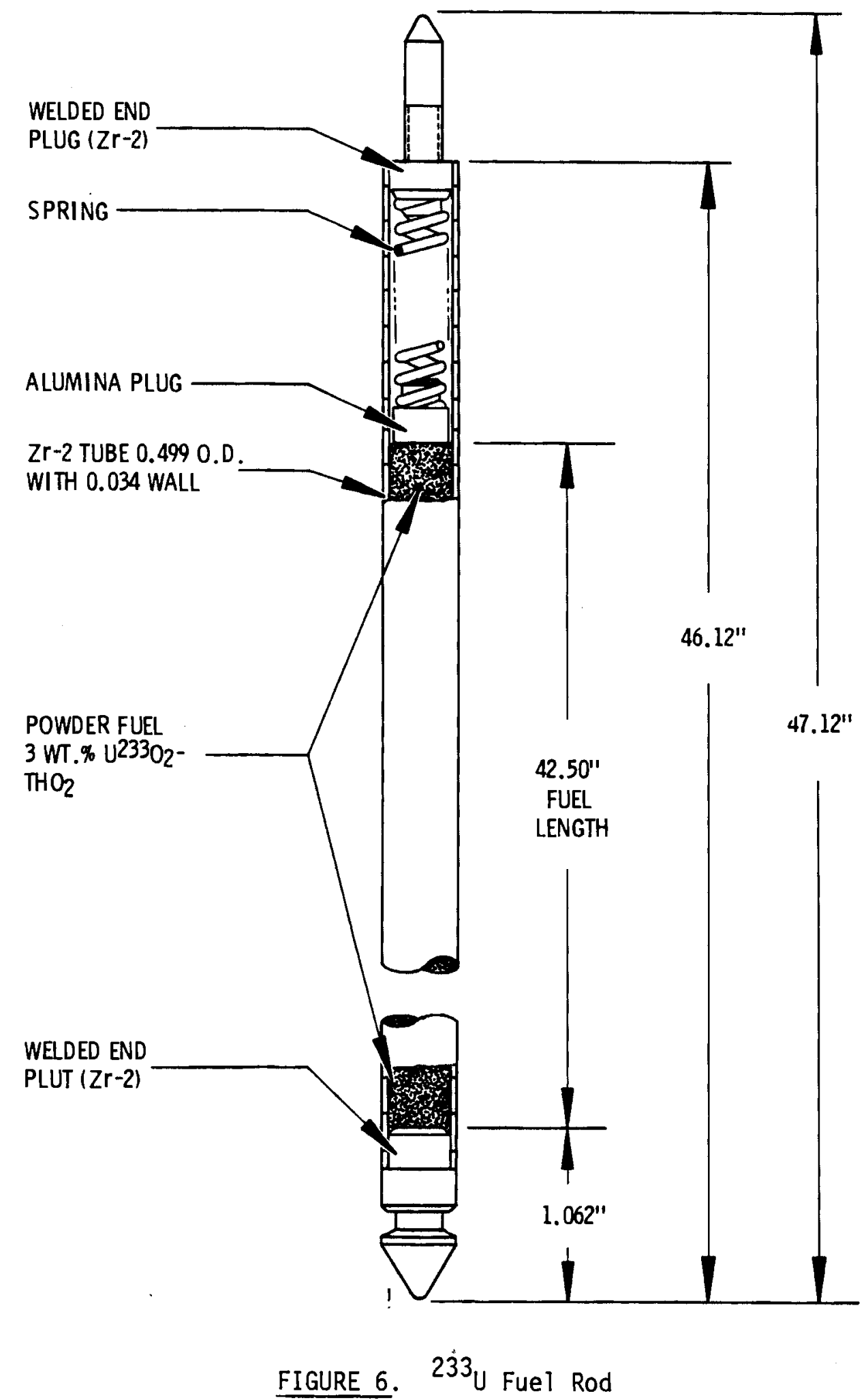




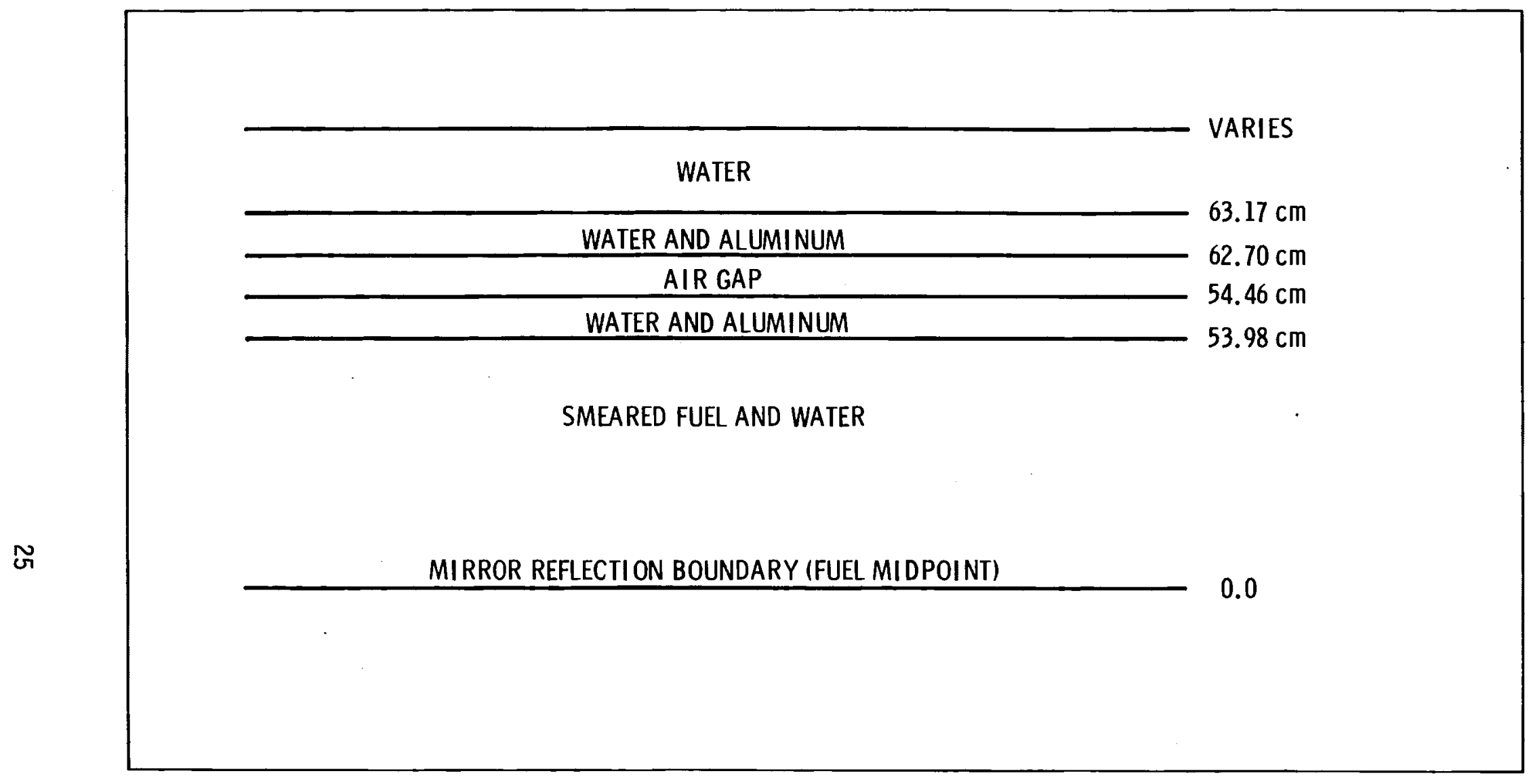

FIGURE 7. Calculational Model for the Top of the Water Filled Tank 


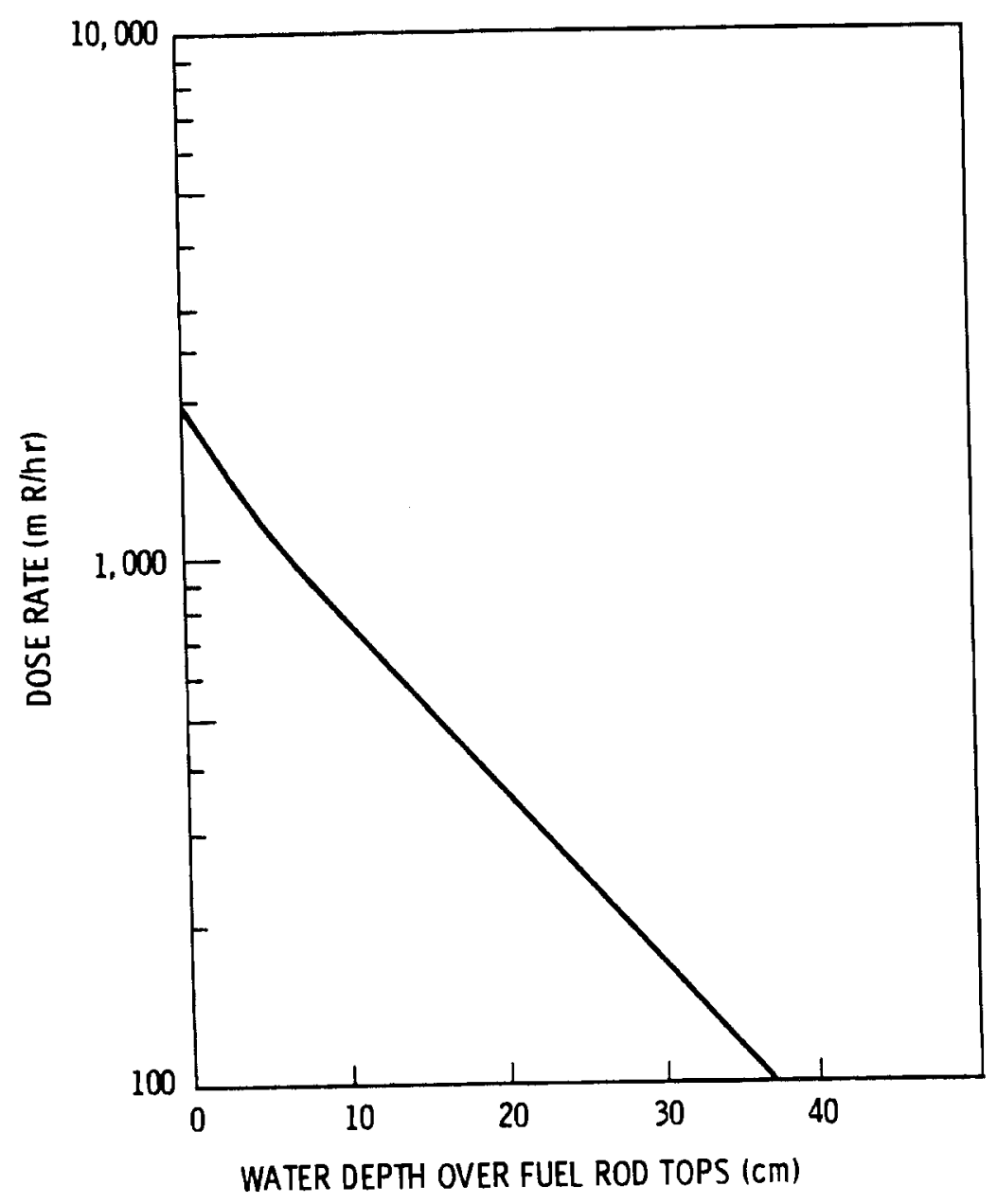

FIGURE 8. Dose Rate on Top of Tank as a Function of Water Thickness

neutron reflector, and for some "freeboard" between the tank top and the water surface, it would not be practical to raise the water level enough to reduce the radiation dose rate over the tank for this lattice to much less than $165 \mathrm{mR} / \mathrm{hr}$. Since experimenters loading rods into lattice plates must spend considerable time above the tank to insert and position the fuel rods, additional shielding would be required to keep radiation doses as low as is reasonably achievable (ALARA). As may be seen in Figure 3, for this gamma spectrum a factor of 10 reduction in dose rate results from about 2 inches of $\mathrm{Pb}$. Consequently, moveable shielding above the experimental tank equivalent to a 2 inch thick layer of $\mathrm{Pb}$ bricks would be required during major fuel rod manipulations. 


\section{CRITICAL EXPERIMENT DESIGN CALCULATIONS}

From the standpoint of criticality safety, critical lattices of primary interest are those with minimum size or a minimum mass of fuel. Consequently a series of three lattices bracketing the corresponding moderator-to-fuel $(M / F)$ volume ratios was planned.

From the standpoint of methods and data validation, highly undermoderated lattices often prove difficult to calculate accurately. Consequently it was also planned to assemble as tight a lattice as could be made critical using the number of fuel rods available (896). Depending on the budget actually made available for experimentation, then, other lattices of intermediate moderate available for experimentation, then, other lattices of intermediate moderation could be added to these experiments.

The information of greatest importance for experiment design purposes is the number of rods required for a critical lattice, for each M/F ratio selected for experimentation. Experimental procedures require that criticality be approached in a series of steps, increasing the lattice loading sequentially. This allows the critical number of fuel rods to be predicted from plots of the inverse lattice multiplication vs the number of rods in the lattice. Consequently, experimentation can be undertaken without highly accurate preliminary calculations.

However, preliminary knowledge of critical lattice size is important to allow design of lattice plates which position both the fuel rods and the control and safety baldes for neutronic control. It is desirable to design experimental lattices so that they can be made critical with both control and safety blades fully withdrawn. This facilitates neutronic calculations of the critical condition by eliminating asymmetric regions of high neutron absorption produced by partially withdrawn neutron absorber blades. It is also important to locate control and safety blades immediately adjacent to critical lattices so that their reactivity control worth is maximized by the neutron flux peaking found there. Consequently, for cylindrical lattices it is desirable to use curved control and safety blades inserted through slots cut in the lattice plates. Locating the slots just outside of a cylindrical lattice which is just 
critical (or slightly subcritical) with the blades fully withdrawn requires accurate preliminary information.

Information from the previous BNL exponential experiments ${ }^{(6)}$ could be used for lattice plate design in the $M / F$ region above 1.0 . However, extrapolation of this information to lower $M / F$ ratios is problematic. Material buckling values $\left(B_{m}^{2}\right)$ are the primary data resulting from exponential experiments. Values of $B_{m}^{2}$ and reflected extrapolation length $(\lambda)$ measured in the BNL experiments on unpoisoned, water moderated lattices are listed in Table 4. Extrapolation of the $B_{m}^{2}$ values to lower $M / F$ ratios is seen to be highly uncertain in the plot of Figure 9. Additional uncertainty in estimating the number of rods required for criticality is introduced by the need to extrapolate the corresponding reflector savings values plotted in Figure 10. Consequently calculations were performed.

TABLE 4. Buckling and Reflected Extrapolation Length for Unpoisoned $233 \mathrm{UO}_{2}-\mathrm{ThO}_{2}-\mathrm{H}_{2} \mathrm{O}$ Lattices (Reference 6)

\begin{tabular}{|c|c|c|c|}
\hline $\begin{array}{l}\text { Lattice } \\
\text { Pitch } \\
\text { (in) } \\
\end{array}$ & $\begin{array}{c}\text { Moderator } \\
\text { Fuel } \\
\text { Volume } \\
\text { Ratio(a) }\end{array}$ & $\begin{array}{l}\text { "Best" } \\
\text { Values of } \\
\text { Measured } \\
\text { B2 }(m-2)\end{array}$ & $\begin{array}{c}\text { "Best" } \\
\text { Values of } \\
\text { Measured } \\
\lambda(\mathrm{cm})(\mathrm{b})\end{array}$ \\
\hline i & & & \\
\hline 0.627 & 0.997 & $75.88 \pm 2.0$ & $7.60 \pm 0.3$ \\
\hline 0.677 & 1.384 & $86.06 \pm 1.3$ & $7.24 \pm 0.17$ \\
\hline 0.716 & 1.7134 & $89.34 \pm 2.0$ & $7.05 \pm 0.3$ \\
\hline 0.771 & 2.1943 & $90.35 \pm 1.6$ & $6.80 \pm 0.2$ \\
\hline 0.854 & 3.0043 & $85.54 \pm 0.8$ & $6.57 \pm 0.1$ \\
\hline 0.971 & 4.2722 & $69.8 \pm 1.0$ & $6.44 \pm 0.15$ \\
\hline 1.172 & 6.8449 & $32.2 \pm 0.2$ & $6.25 \pm 0.05$ \\
\hline 1.335 & 9.2747 & $-1.22 \pm 0.3$ & $6.65 \pm 0.05$ \\
\hline
\end{tabular}

(a) Solutions at normal room temperatures $\left(220^{\circ} \mathrm{C}\right)$.

(b) Identified in the text of Reference 6 as "reflector savings." 


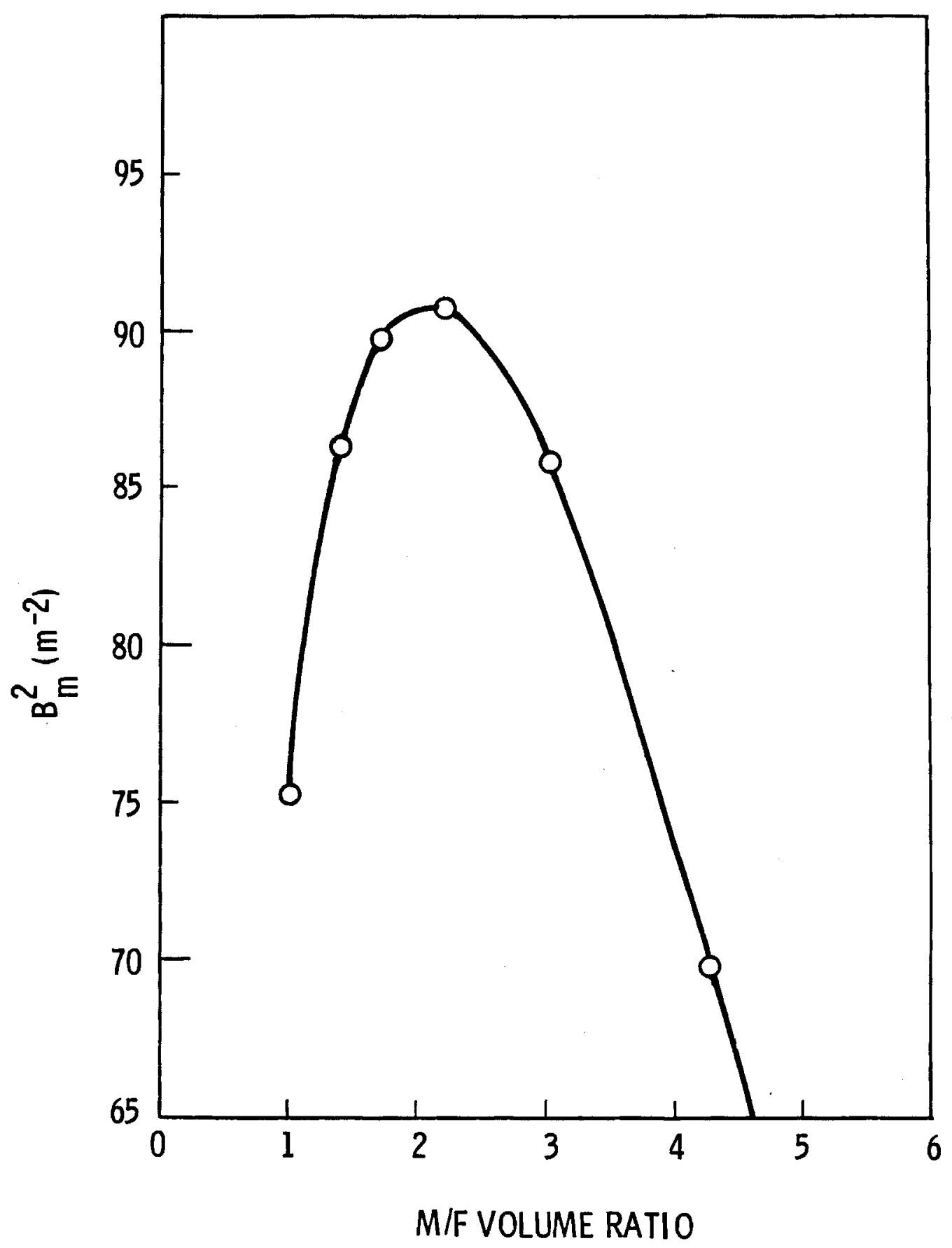

FIGURE 9. Buckling Valves Measured in the BNL Experiments 


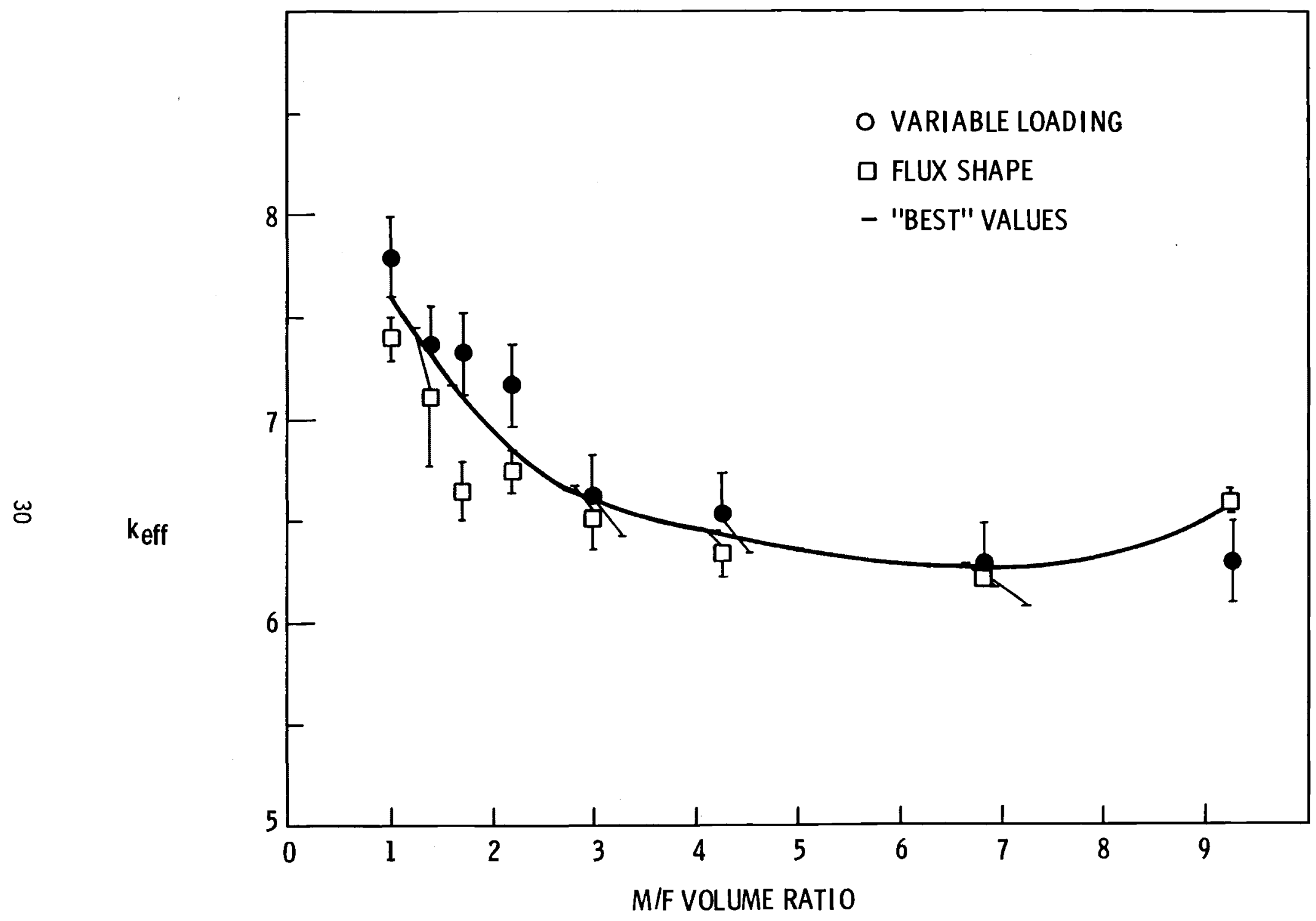

FIGURE 10. Reflector Savings Measured in the BNL Experiments 
Calculations of the critical number of fuel rods for triangular lattices of the ${ }^{233} \mathrm{UO}_{2}-\mathrm{ThO}_{2}$ fuel pins were performed using the HFN $(21)$ one-dimensional diffusion-theory code with four-group cross section sets prepared using the EGGNIT-II ${ }^{(22)}$ and BRT ${ }^{(23)}$ codes. Important cross sections in the EGGNIT library are from ENDF/B-IV, (24) while thermal cross sections in the BRT library are older, mostly from ENDF/B-II. Calculations were performed for a lattice having a $M / F$ ratio of 0.8 , and also for lattices having the same $M / F$ ratios as those measured in the BNL experiments.

The results of these calculations were compared with predictions obtained from the $B N L$ measurements of $B_{m}^{2}$ and $\lambda$, where

$$
B_{m}^{2}=\left(\frac{2.4048}{R_{c y l}+\lambda}\right)^{2}+\left(\frac{\pi}{h+2 \lambda}\right)^{2} \text {. }
$$

The required number of rods was obtained by dividing the core cylindrical radius $R_{c y l}$ by the area of a single pin cell radius

$$
r \operatorname{cell}^{2}=\frac{\sqrt{3}}{2 \pi} p^{2}
$$

where $p$ is the pitch of the hexagonal lattice. The results are presented in Figure 11 and Table 5, where it is seen that the calculations predict fewer rods for each lattice than the predictions using $\mathrm{B}_{\mathrm{m}}^{2}$.

For the purpose of planning an experiment at low $M / F$, underprediction of the number of rods required is unacceptable. (Criticality must not require more rods than are on hand.) Consequently, an estimate was made of the bias in the calculations, which was then used to "correct" the calculated numbers. The method by which bias was estimated is described in the following section. The "corrected" values are also presented in Figure 11 and Table 5. The "corrected" calculated values agree with or exceed those estimated using $B_{m}^{2}$ values.

The "corrected" calculations indicate that a lattice having a M/F volume ratio of 0.8 would be critical with about 829 rods. It was therefore concluded that an experiment at $M / F=0.8$ would be feasible with the 896 rods available. 


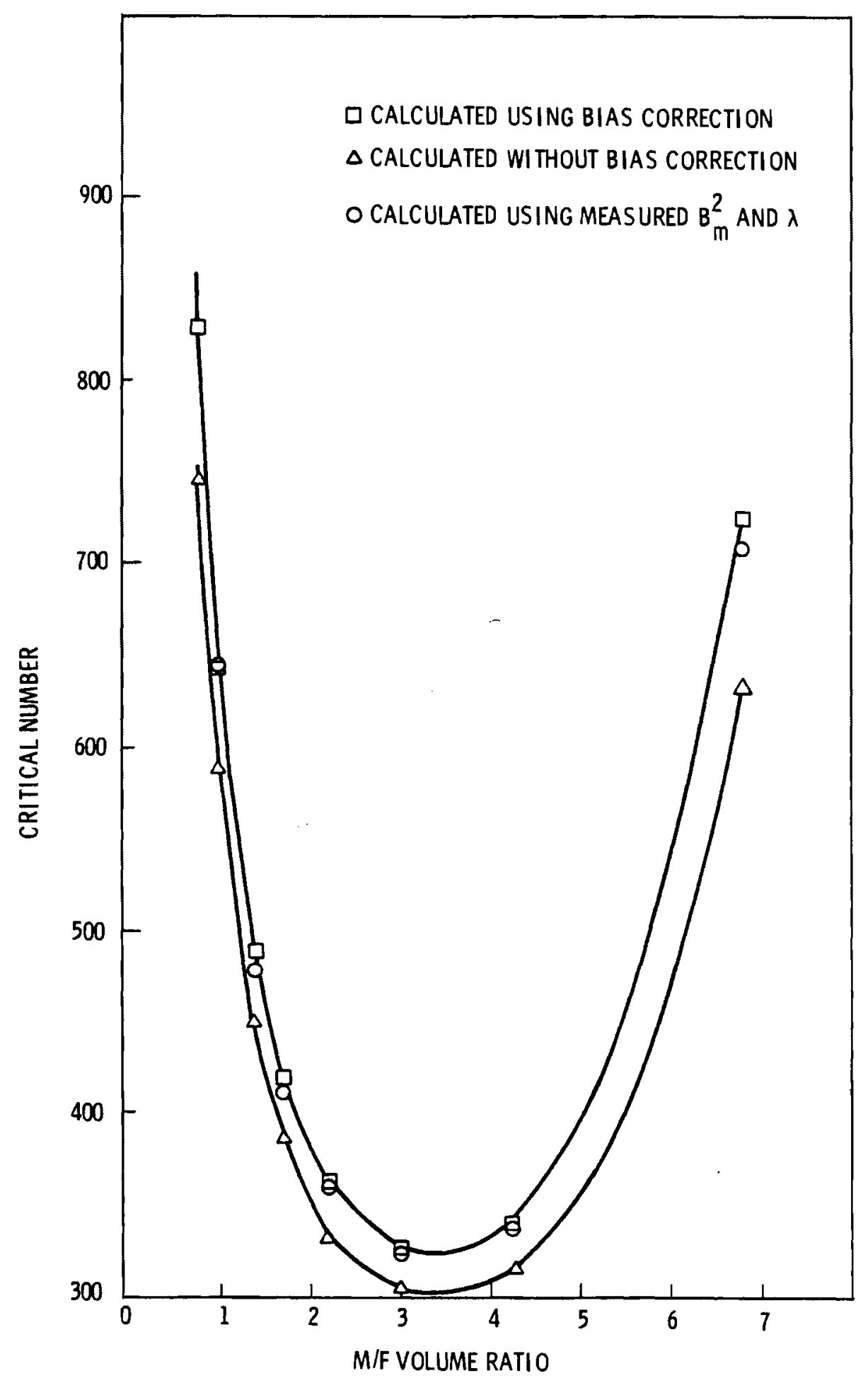

FIGURE 11. Number of Rods Required for Criticality 
TABLE 5. Predicted Number of Rods Required for Criticality

\begin{tabular}{|c|c|c|c|}
\hline $\begin{array}{c}\text { M/F } \\
\text { Ratio }\end{array}$ & $\frac{\mathrm{Ca}}{\text { Direct }}$ & $\begin{array}{l}\text { "ulated } \\
\text { "Corrected" }\end{array}$ & $\begin{array}{c}\text { From Measured } \\
\text { B }{ }_{\text {m }} \\
\end{array}$ \\
\hline 0.8 & 748 & 829 & -- \\
\hline 0.997 & 590 & 645 & 647 \\
\hline 1.384 & 450 & 489 & 478 \\
\hline 1.7134 & 386 & 420 & 412 \\
\hline 2.1943 & 337 & 364 & 360 \\
\hline 3.0043 & 304 & 327 & 325 \\
\hline 4.2722 & 316 & 343 & 339 \\
\hline 6.8449 & 634 & 725 & 704 \\
\hline
\end{tabular}

Reduction of the M/F ratio much below 0.8 , however, might result in inability to achieve criticality. Consequently, 0.8 was selected as the M/F ratio to be used for the low-moderated, large-lattice experiment which was planned. The hexagonal pitch of such a lattice is $1.524 \mathrm{~cm}$. A M/F ratio of 0.8 is $20 \%$ smaller than that of the most undermoderated lattice investigated at BNL. A critical experiment at this M/F ratio would significantly extend the range of existing data, in a region where calculated results often vary rapidly as a function of M/F ratio. Consequently, it would be quite useful for the testing of calculational methods and cross section data. 



\section{CALCULATIONS OF THE BNL EXPERIMENTS}

The subcritical lattices used in the BNL exponential experiments were analyzed using the same codes and cross sections used for experiment planning. The results of these calculations provided an estimate of calculational bias which was used to "correct" the number of fuel rods estimated to be needed for critical lattices. In addition, these results exhibit scatter at low $\mathrm{M} / \mathrm{F}$ ratios. Scatter at low $M / F$ ratios has also been found in other calculational analyses of the BNL experiments. It was hoped that the critical experiments planned for this program would help determine whether the scatter is an artifact of the calculational methods, or whether it results from the experiments or from approximations inherent in the theory of exponential experiments.

In a subcritical exponential pile a steady-state neutron flux is maintained by a neutron source at one end of the lattice. The resulting neutron flux falls off exponentially with axial distance from the source (in a long pile), hence the name exponential experiment. Neutronic calculational codes normally used to calculate the effective multiplication constant, $k_{\text {eff }}$, of fissile lattices can also be used for calculations of exponential experiments. However neutrons leaking into the lattice from the source must be included in the calculation. As a result of this inleakage the interpretation of the results changes somewhat. With neutron inleakage a calculated value of $k_{\text {eff }}=1.0$ no longer indicates criticality, but rather that a neutron balance exists between successive generations of neutrons. In other words, for a lattice with neutron inleakage a calculated value of $k_{\text {eff }}=1.0$ indicates that neutron inleakage plus multiplication balances outleakage plus absorption, so that a steady state flux is predicted. This is the physical situation in an exponential experiment. Deviations of calculated values of $k_{\text {eff }}$ from unity indicate that the code incorrectly calculates neutron in or outleakage, absorption, or multiplication.

In many one- and two-dimensional neutronics codes neutron transport in the third, or axial direction is treated by means of a buckling approximation. Only neutron transport perpendicular to the axial direction is explicitly calculated. Neutron losses due to axial migration are incorporated through an axial buckling term: 


$$
B_{z}^{2}=\left(\frac{\pi}{h+2 \lambda}\right)^{2}
$$

whose value is input to the calculation. Now the buckling concept derives from the analytical solution of the diffusion equation for the fundamental mode neutron flux. In a cylindrical critical pile the flux has a cosine shape in the axial direction. The value of $B_{z}^{2}$ indicated above is the negative of the eigenvalue of the Laplacian operator which causes the cosine solution to vanish one extrapolation length beyond the physical boundaries of the lattice. The physical cause of this flux shape is axial leakage of neutrons, and the computer programs incorporate the appropriate amount of axial leakage into their neutron balance computations.

The analytic solution to the diffusion equation in the axial direction of an exponential pile is a decaying exponential having a relaxation length $\ell$. The negative of the eigenvalue of the Laplacian operator for this flux solution is

$$
B_{z}^{2}=-\frac{1}{l^{2}}
$$

When this negative value is input to the computer codes the neutron leakage becomes negative - i.e., it becomes a neutron source of strength appropriate to maintain the necessary flux shape.

Therefore, for codes which treat axial neutron transport using the buckling approximation, the incorporation of source neutrons into the calculation is particularly simple (as long as the source is a planar, fundamental mode source located at one end of the lattice under investigation). The dimensions perpendicular to the axial direction of the actual subcritical lattice under consideration are input, along with a negative buckling whose magnitude is calculated from the appropriate flux relation length. In calculations of the BNL experiments the measured values of the relaxation length were used. They were obtained, along with the lattice sizes, from the original report of the experiments. (10) The values used are listed in Table 6. (Although 
TABLE 6. Lattice Parameters of BNL Exponential Experiments Calculated

\begin{tabular}{|c|c|c|c|c|}
\hline \multirow[b]{2}{*}{$\begin{array}{r}\mathrm{M} / \mathrm{F} \\
\text { Ratio } \\
\end{array}$} & \multirow[b]{2}{*}{$\begin{array}{l}\mathrm{H} / 233 \mathrm{U} \\
\text { Ratio } \\
\end{array}$} & \multirow[b]{2}{*}{$\begin{array}{l}\text { Number of } \\
\text { Fuel Rods }\end{array}$} & \multicolumn{2}{|c|}{ Flux Relaxation Length $\ell(\mathrm{cm})$} \\
\hline & & & Corrected* & Heasuredt \\
\hline 0.997 & 107 & 511 & 39.57 & 39.297 \\
\hline 1.384 & 150 & 397 & 43.58 & 45.370 \\
\hline 1.7134 & 186 & 343 & 39.76 & 44.575 \\
\hline 2.1943 & 238 & 301 & 44.5 & 44.813 \\
\hline 3.0043 & 327 & 271 & 45.18 & 46.304 \\
\hline 4.2722 & 466 & 265 & 38.04 & 38.933 \\
\hline 6.8449 & 747 & 433 & 39.97 & 39.884 \\
\hline
\end{tabular}

\footnotetext{
*From Table I, p. 271 of Reference 10. Corrections remove spurious $(\gamma, n)$ source using measurements taken with $C d$ covered thermal column.

+From Tables II-VIII, pp. 272 - 278 of Reference 10.
}

experiments were performed for a series of lattices of different numbers of rods at each lattice pitch, only the largest lattice was calculated here.)

Values of $k_{\text {eff }}$ calculated for the BNL exponential lattices are presented in Figure 12 and Table 7 . They all exceed 1.0, indicating that the neutron balance achieved in the experiment is not reproduced in the calculation. Inleakage plus multiplication consistently exceed outleakage plus absorption.

All but one of the lattices calculated contain more than 75 percent of the predicted critical number of fuel rods (see Tables 5 and 6 ). Therefore, it is to be expected that calculations of critical lattices would similarly overpredict $k_{\text {eff }}$. Consequently, lattices calculated to be critical would be too small. Calculated critical lattice sizes should be increased to yield a corresponding overprediction of $\mathrm{k}_{\text {eff }}$.

A bias estimate is drawn on Figure 12 which is conservative from the standpoint of lattice design for critical experiments. A lattice sized to yield a calculated $k_{\text {eff }}$ agreeing with the bias estimate for its $M / F$ ratio is expected to be critical or supercritical. This is important for determination of the lowest M/F ratio for which a critical lattice can be constructed using a limited number of fuel rods. 


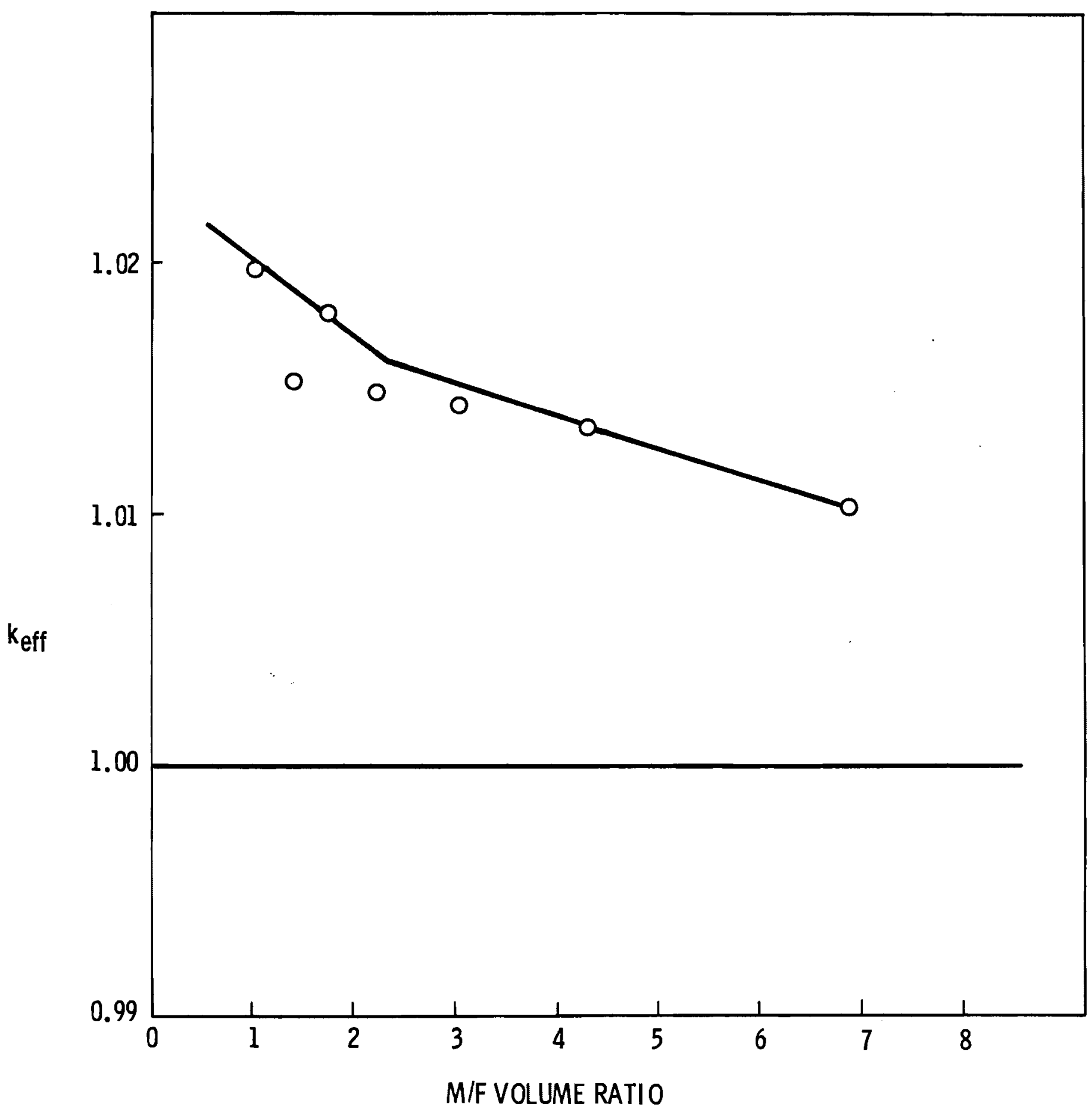

FIGURE 12. Keff Values Calculated (Including Axial Neutron Leakage) for the BNL Experiments, Plus Bias Estimate 
TABLE 7. Values of $k_{\text {eff }}$ Calculated for the BNL Experiments. Also Values from the Bias Estimate of Figure 12

\begin{tabular}{|c|c|c|}
\hline \multirow[b]{2}{*}{$\begin{array}{r}\text { M/F } \\
\text { Ratio } \\
\end{array}$} & \multicolumn{2}{|c|}{ keff } \\
\hline & $\begin{array}{l}\text { BNL } \\
\text { Experiments }\end{array}$ & $\begin{array}{r}\text { Bias } \\
\text { Estimate }\end{array}$ \\
\hline 0.80 & - & 1.0207 \\
\hline 0.997 & 1.0197 & 1.0200 \\
\hline 1.384 & 1.0153 & 1.0189 \\
\hline 1.7134 & 1.0180 & 1.0180 \\
\hline 2.1943 & 1.0149 & 1.0165 \\
\hline 3.0043 & 1.0145 & 1.0152 \\
\hline 4.2722 & 1.0136 & 1.0136 \\
\hline 6.8449 & 1.0104 & 1.0104 \\
\hline
\end{tabular}

Numerical values of the bias estimates for the $M / F$ ratios of the BNL experiments are listed in Table 7 , including the bias estimate for $M / F=0.8$. These bias estimates were used to "correct" the numbers of fuel rods calculated to be required for criticality in Section 7 . This was done using the results of the critical search routine which finds the lattice size for which $k_{\text {eff }}=1.0$. A linear extrapolation of the radii for which $k_{\text {eff }}$ was calculated to be closest to 1.0 was used to determine the lattice size corresponding to the bias estimate of $k_{\text {eff }}$. The results have already been presented in Figure 11 and Table 5. It is seen that the "corrected" number of rods always exceeds that estimated from $\mathrm{B}_{\mathrm{m}}^{2}$ values, but by a small fraction. Consequently it is estimated that a lattice having $M / F=0.8$ would be critical or supercritical if it contained 829 rods. This number of rods is $93 \%$ of the total rods available. It is acceptibly close to using all rods, yet leaves a small contingency should the bias estimate be low.

The values of $k_{\text {eff }}$ calculated (with axial neutron inleakage included) for the BNL experiments and plotted in Figure 12 exhibit scatter at low M/F ratios. A possible source for this scatter might lie in corrections to measured values of the flux relaxation length $\ell$ which were made to eliminate the effects of spurious neutrons from $(\gamma, n)$ reactions. In Table 6 it is seen that the corrections are much larger for the lattices having M/F ratios of 1.4 and 1.7. However, 
this does not correlate with the particularly high values of $k_{\text {eff }}$ calculated for $M / F$ ratios of 1.0 and 1.7. Consequently it is unlikely that the source correction is the cause.

The scatter in values of $k_{\text {eff }}$ calculated for these experiments is also found in calculations by others in which the subcritical lattices actually investigated are modeled and the axial inleakage of source neutrons is incorporated. Figure 13 displays the results of calculations by U110, Hardy and Steen ${ }^{(25)}$ of BAPL. Two sets of points are plotted. Those without error bars are from transport calculations (P7MG) code) using cross sections prepared by Monte Carlo cell calculations (RCP01 code) with source neutrons included as axial inleakage through $B_{z}^{2}=-1 / \ell^{2}$. Those with error bars are from Monte Carlo calculations in which the lattices were explicitly modeled in two dimensions (RCPOl code) and axial inleakage was incorporated using the results of transport calculations (P7MG code). Scatter is also evident in these results at low M/F ratios, particularly in the Monte Carlo results which avoid the "... approximations involved in the homogenization of the lattices." Furthermore, the direction of displacement from a smooth curve of points calculated for corresponding M/F ratios is similar in all calculations. It was hoped that the critical experiments planned would help determine whether this scatter is an artifact of the calculational methods or whether it results from the experiments themselves. 


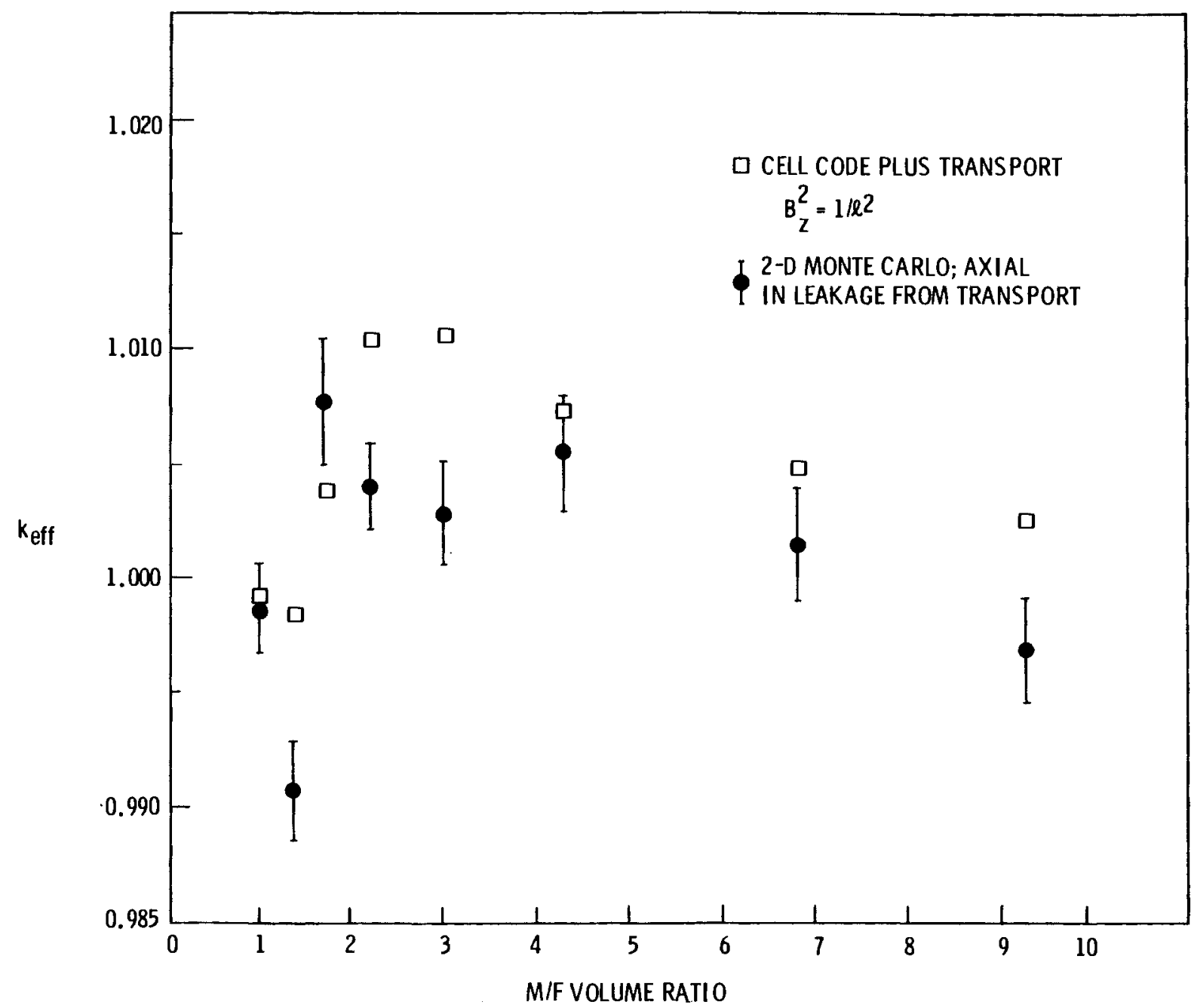

FIGURE 13. BAPL Calculated Values of $k_{\text {eff }}$ for the BNL Experiments 


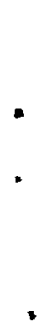




\section{FUEL ROD ACQUISITION ACTIVITIES}

The fuel rods which were sought for experimentation were stored at BAPL where they had previously been used for neutronics experiments in heavy water moderator. (16) They were available at no charge, as excess property. When discussions were initiated with BAPL personnel concerning the possibility of obtaining the rods it was learned that planning was underway to dispose of the rods by shipping them for burial at the Idaho Transuranic Storage Area (ITSA). Preliminary planning for this had already begun, and BAPL gratiously agreed to continue and complete shipment planning, with PNL as the new destination. DOT Specification 6M drums ${ }^{(26)}$ were the only containers for which BAPL had an NRC Certificate of Compliance authorizing shipment of ${ }^{233} U$ bearing material, so they were chosen for use as shipping containers.

The 6M drums are commonly used in the 55 gallon size. However, to accommodate the 48 inch long fuel rods, plus additional required packing material, the length had to be increased to about 62 inches. This resulted in a drum capacity of about 100 gallons. This size increase plus a combination of DOT requirements led to design of containers which could each hold a maximum of 12 fue 1 rods.

Two DOT requirements combined to severely limit the number of rods allowed per container. Radiation dose rates outside a vehicle used exclusively for a single shipment may not exceed $10 \mathrm{mR} / \mathrm{hr}$ at a distance of 6 feet from the vehicle surface. (27) Also, the weight of each loaded 6M container may not exceed 640 lbs. (26) The drums, plus their lining of industrial cane disks, plus the required inner $2 R$ container of steel pipe, would weigh about $400 \mathrm{lbs}$. Lead shielding was required to attenuate gamma radiation from the rods. Due to the drum weight limit, however the amount of $\mathrm{Pb}$ which could be included in the containers was severely limited. To minimize the amount of $\mathrm{Pb}$ required, it was located inside the inner container just outside the rods.

The final container design specified by BAPL called for 0.75 in. of $\mathrm{Pb}$ having an inner diameter of $2.25 \mathrm{in}$. (about $150 \mathrm{lb}$ of $1 \mathrm{~b}$ ). This thickness of $\mathrm{Pb}$ attenuates gamma fields from ${ }^{233} \mathrm{U}$ fuel by a factor of about three. 
Additional information on the design is provided in the Appendix, where the design requirements specified to the manufacturer by BAPL are reproduced.

The three fourths inch thickness of $\mathrm{Pb}$ surrounding 12 fuel rods was calculated to yield radiation fields at the drum surface well below $100 \mathrm{mR} / \mathrm{hr}$. Grouping 20 drums along the center line of the semi-trailer used to ship the drums was planned in order to meet the radiation limits outside the trailer walls. The requirement that dose rates to the driver and any other normally occupied position in the vehicle not exceed $2 \mathrm{mR} / \mathrm{hr}^{(27)}$ would be achieved by providing whatever spacing was required between the front of the trailer and the forwardmost drum. This was not expected to reduce the allowed load below 20 drums.

BAPL purchased 25 of the drums from a commercial fabricator during late FY 1979. It was planned to ship the rods in four batches starting in August. Two month intervals were planned between shipments to allow time for shipping and return, plus loading and unloading. PNL agreed to pay for the drums (\$750 each) plus shipping costs. They would be useful for on-site transport and perhaps rod disposition after experimentation was complete.

As negotiations proceeded on drum design and shipping arrangements, a complication was discovered by BAPL personnel. Upon receipt at BAPL the rods had been found to have smearable surface alpha contamination up to $250 \mathrm{pCi} /$ $100 \mathrm{~cm}^{2}$, with most rods measuring in the range of 10 to $85 \mathrm{pCi} / 100 \mathrm{~cm}^{2}$. Following experimentation the rods had been returned to their original shipping containers for storage. Although all but 32 of the rods had been cleaned for use in experiments, the potential for recontamination from the drums existed. No records were maintained of the condition of the drums or of the pattern of rod reloading. The actual condition of the rods could not be determined as BAPL personnel were unwilling to open the drums prior to initiation of actual transfer operations to shipping containers.

Due to the possibility of smearable alpha contamination on the rods BAPL was persuaded to add a removable inner container to their shipping container design to prevent internal contamination from the rods and also to prevent the spread of loose alpha contamination when the drums were unpacked. Preliminary plans were made for fabrication of 1 iners from 6061 T6 aluminum 
and caps from chrome plated steel. Liners were not fabricated, however, due to withdrawal of the request for the rods.

Upon notification that funding for experimentation would not be provided PNL cancelled its order for the rods and the shipping containers. The containers, plus others to be fabricated, will now be used by BAPL to ship the rods to ITSA and to contain them in storage there. 


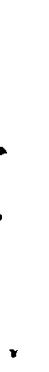




\section{APPENDIX}

DESIGN REQUIREMENTS FOR SHIELDED CONTAINERS FOR SHIPMENT OF KILORODS 
Ealowive to

\section{APPENDIX: DESIGN REQUIREMENTS FOR SHIELDED CONTAINERS FOR SHIPMENT OF KILORODS _...}

Department of Tranoportation Spocification 6n Drum having a DOF Spec 2R lnacr vessal and lead ahielding as specteled below and as shown in Floures 1 and 2. The drums are to neet all requirements of $49 \mathrm{CFR} 178.104$.

\section{A. Requirements for the 61 Drum}

1. The outer shell shall be a opecial s1ze DOT spec 17C drum per $49 \mathrm{CFR} 178.115$ of epproxdmaly $100 \mathrm{mll}$ capacity constructed of galvanized steel. The 64 drum 1nside height shall be approximately 60 inches, made by velding appropriate lengthe of two 55 pellon drws, in ordar to accommodate a DOT spec 2R container of 49.5 inches high (inside belght of $2 R$ exelusive of cep).

2. The drun IId shall contaln a 1 inch dsangter veat hole at the center. The rent hole ahell be pluged with a bleck polyetigylene Ce plus BPF-1 insert (Protective Clowure, Inc.) or epproved equivilent. the lesert abll be sevled wth a illcon type scalant or approved altermate. Inls vant hole 1s an "equivelent device" per 49 GR 178.104-3(e)(2) and is specified in place of the four $1 / 2$ inch dianstar. reat boles on the sides of the drun an deseribed in that section of $49 \mathrm{CHR}$.

3. The DOT Spoc 2R Inner contalnment reasel shall be cupported and centered by solid Industrial cane fiberboand discs couplyting w1th $49 \mathrm{CFR} 178.104-3(\mathrm{c})(1)$. The cane fiberboard rings shall be compatible vith a 4-inch diamoter Bchedule 40 pipe $2 R$ container.

4. Plyrood d18ce shall be used to couply with 49 GR 278.104-3(e). The discs shall be glued in place vith vaterproof elve.

5. A layar of Cerafelt or Carablanket inoulation (Johns-yardile) bhall be provlded between the drum lid and the cane f1barboard. The Insulation shall have a density of six to elotht pounds par cuble foot and shall be at least 18 inches in dismeter. The Inoulation aball be of sufflelent thicknese ( $\frac{1}{2}$ Inch mintmum) to be compressed wen the drum ild is in place. The insulation stall be sttached to elther the dre 11d or the top of the cane flberboard.

6. Two fingerhales shall be provided in each of the ease fiberboard dises and rings that need to be rewoved to provlde access to the spec $2 R$ inner container. The fingernoles shall be about one Inch in diameter and shall be located approximately $1 \frac{1}{2}$ inches from the outer edge and 180 degrees apart. 
7. The $5 / 8$ Inch clooure bolt required per 49 CR 278.204-4(a) shall most the following conditions:

a. Be caduitun coated

b. Have elevea threade par loch

c. Have a 15/16 inch hex head

d. Be 4 inches 1008 with about $3 \frac{1}{2}$ inch thread length

o. Bave a th lach dinater through hole one inch frou the threaded end of the bolt.

8. The cuter drum sholl be painted with one primor cont and one coat of white paint. The paint shall be sultable for golvanized motal.

9. A stainleas steel ram plate shell be weldod to the side of the drum between the top and second rolling hoope. the rame plate shell contain the follourlng Information engraved in letters and minorie at leant $\frac{1}{2}$ lnoh blop:

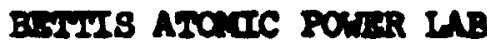

WEST ITHWII EA 15222

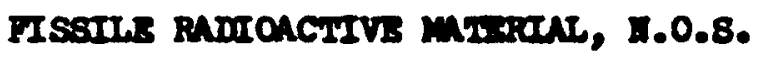

DOT-6x TAPB B 16-200-

$\mathrm{USA} / 5908 / \mathrm{B}$ ( )P

Dingy ro. Baw

GROSs WHait LES

(Drum vamifecturer's Ident1flcation, per $49 \mathrm{CFR} 173.24(\mathrm{c})(11)$

where * Is the Year of Mamuencture.

* Is a throe-digit drum muber, beginning with number 401.

w* Is a three-digit muber to be engraved by Bettis at time of use.

The seam between the oan plate and obell of the 611 dren ahall be sealed vaterelght with opory plantic.

B. Reruirements for the Spec 2R Contalner

The coatalner shall courly with $49 \mathrm{CFR} 178.34$ and the followIng additioal requirements and/or clarifications: 


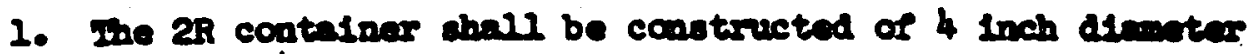
scheinule 40 steal pipe.

2. The botton cloure shall be t inch thick (notorl) steel plate velded to the botton of the pipe. A rull penotration weld is required; welding shall be per 49 CrR $173.24-(c)(4)$.

3. The top closure shall be 4 inch schedule 40 plpe cap couplying with $49 \mathrm{CFR} 178.34-4(\mathrm{a})(1)$ and $178.104-3(\mathrm{~b})$.

4. The inside length of the $2 R$ (exclusing the cap belogt) from the bottom plate to the top of the 2R plpe shall be $49.5 \pm \frac{1}{4}$ inches.

5. Each p1pe cap or 2R pipe wall aball be marted vith the words "FISSIIS RADIOACIIV MLtRIAI" in th inch hiob letters in addition to the marking requirement of 49 CHR 178.34-1(b). The letters shall be embossed or die stemped directly cato the cap or plpe or by welding a metal plate bearing these words to the $2 R$ cap or pipe.

6. The inside and cutside of the 28 contalner shell be cleand to remove any cutting o1l, grease, and so forth.

7. The cutelde of the $2 R$ whall be palnted with cos cent red wetal priter. Do not palint the plpe threads.

8. The Inting compond uned to coply vath $49 \mathrm{GR} 278.34-4(a)(1)$ shall NOT be applied by the mameracturer. Bott1s whll epply a luting coupound at the time of uee.

C. Requirements for the Iead shielding

1. A solid lead dise, $4.0+0, \frac{1}{4}$ lnch dianeter by $0.5 \pm 1 / 16$ Inch thick, aball be located at the Inside botton of the $2 R$ Inner container.

2. A lead cylindar of $3.75+t$, 0 inch outelde alemetor by 0.75 inch thiek, revilting in en inside diemoter of 2.25

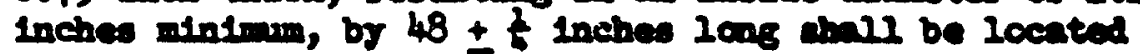
Inside the $2 R$ container. " me cylinder will reat on the 0.5 Inch thick lead disc. Inis lead cylinder wo be memuractured in sections provlded the sections overiep axdaly to provide essentialiy a unifors crose section alcos Its length.

3. A solsd lead dise, $4.0+0, \frac{t}{4}$ inch dineter by $0.5+1 / 16$ Inch thick, aboll be located on tor of the land cylinder at the top of the 2R. A strip of tape, riberglass reInforced or equivaleat strength, shall be looped arcumd the dise with the ends taped together and extending about 4 Inches above the disc to serve as a lifting device. 


\section{Enelocure to}

MAPD-LP (IM)DE-329

4. Iunctionel check - The manfacturese chall control the I.D. of the lead cylinder to enours that twalve dowel pins of 0.5 inch diemeter by 48 inches long can be placed inside the lead cylinder without exwerting excessive force. 
GM/ZR DRUM DESIGN DETAILS

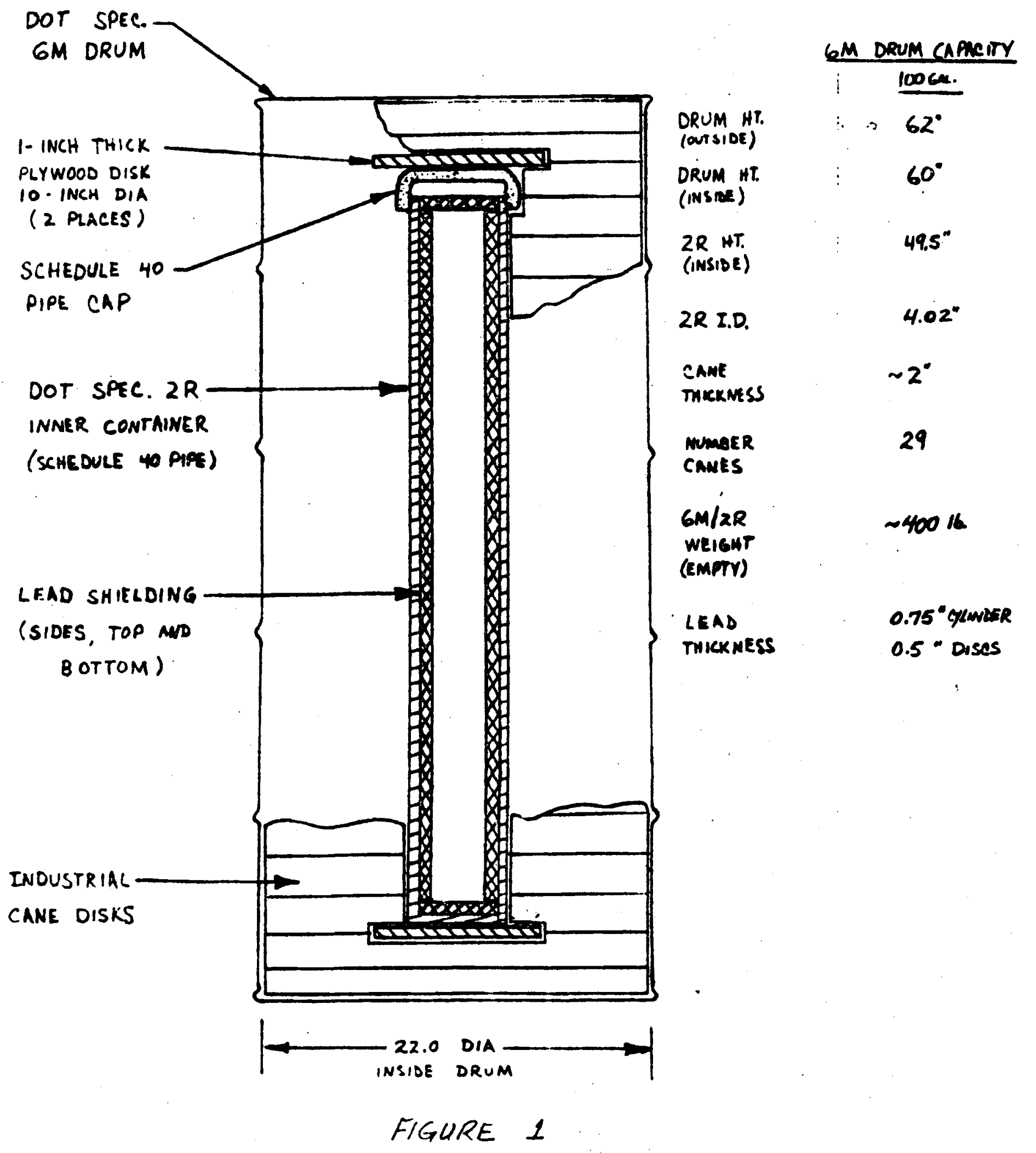


Dealowe to

DUPD-LP(I) inen-329

Assemriy ArRANGEMENT OF LEAD SMELDING FOR LONE KILORODS

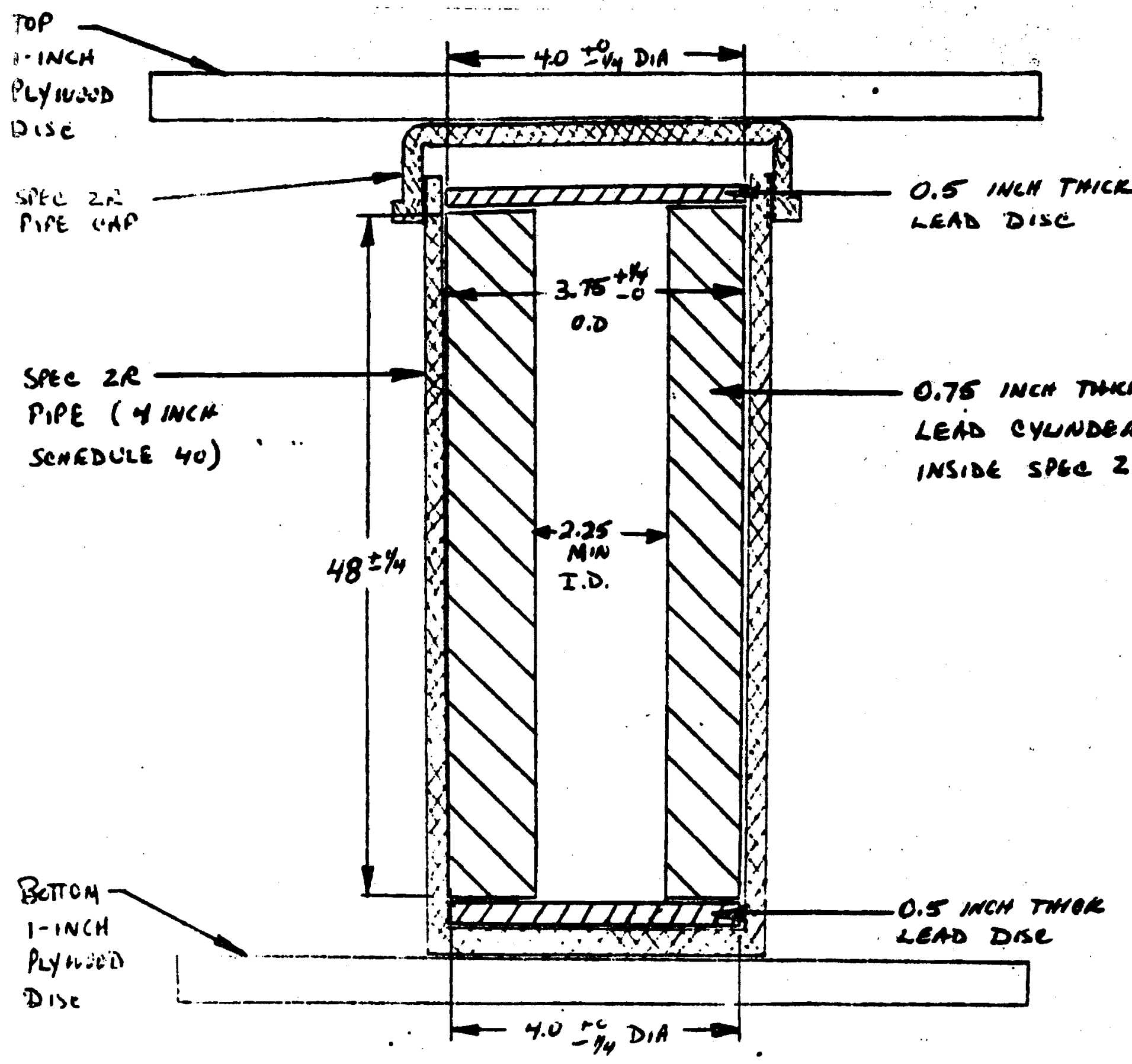

FIGURE 2

6 


\section{REFERENCES}

1. L. C. Davenport, Sources of Neutronics Data Involving Thorium or ${ }^{233} \mathrm{U}$ and Light Water Moderation, PNL-2917, Pacific Northwest Laboratory, Richland, WA, November 1978.

2. B. F. Gore, Compilation of Criticality Data Involving Thorium or ${ }^{233} \mathrm{U}$ and Light Water Moderation, PNL-2080-12, Pacific Northwest Laboratory, Rich Tand, WA, JuTy 1978.

3. J. A. Mitche11, Ed, BMU Series of ${ }^{233} U$ Fueled Critical Experiments, WAPD-TM-1117, Bettis Atomic Power Laboratory, West Mufflan, PA, January 1975.

4. G. G. Smith, J. P. Semans and J. A. Mitche11, Eds, ${ }^{233}$ U Oxide-Thorium Oxide Detailed Cell Critical Experiments, WAPD-TM-1701, Bettis Atomic Power Laboratory, West Mifflin, PA, Octover 1974.

5. J. J. Ul10, J. Hardy, Jr., and N. M. Steen, "Review of Thorium - $233 \mathrm{U}$ Cycle Thermal Reactor Benchmark Studies, Symposium Proceedings: Nuclear Data Problems for Thermal Reactor Applications, EPRI NP-1098; Electric Power Research Institute, Palo Alot, CA, June 1979.

6. H. H. Windsor, W. J. Tuney and G. A. Price, "Exponential Experiments With Lattices of Uranium-233 0xide and Thorium Oxide in Light and Heavy Water," NSE 42, 150-161 (1970).

7. S. C. Bhatt, R. L. Crowther, G. D. Galloway and R. A. Walters, "BWR Methods Comparison with Throium Lattice Benchmarks," Trans. Am. Nucl. Soc., 27, $920(1977)$.

8. R. I. Smith and G. J. Konzek, Clean Critical Experiment Benchmarks for Plutonium Recycle in LWR's, EPRI NP-196, Electric Power Research Institute, Palo A1to, CA, April 1976.

9. R. E. Brooksbank, J. P. Nichols and A. L. Lotts, "The Impact of Kilorod Operational Experience on the Design of Fabrication Plants for 233 U-Th Fuels," Thorium Fuel Cycle, CONF 660524, P321 USAEC Division of Technical Information Extension, Oak Ridge, TN, February 1968.

10. G. A. Price, Uranium-Water Lattice Compilation Part I, BNL Exponential Assemb lies, BNL-50035 (T-449), Brookhaven National Laboratory, Upton, NY December 1966.

11. H. H. Windsor, "An Interpretation of Reflector Savings Measured in WaterModerated and Reflected Exponential Experiments," NSE 33, 139-141 1968. 
12. W. B. Henderson, "Analysis of Critical Experiments Containing GadoliniumPoisoned Fuel" Trans. Am. Nucl. Soc., 21, 457 (1975).

13. R. I. Smith, D. F. Newman, G. J. Konzek, "Experimental Power Normalization Factors for Battelle Plutonium Recycle Measurements," EPRI 348, Electric Power Research Institute, Palo Alto, CA June 1975.

14. Energy Systems Department, Technical Specifications for the Critical Mass Laboratory, BNWL-MA-86, Pacific Northwest Laboratory, Richland, WA, (1atest revision February 15, 1979).

15. E. D. Arnold, "Radiation Hazards of Recycled ${ }^{233}$ U-Thorium Fuels, "Proceedings of the Thorium Fuel Cycle Symposium, TID-76-7650; Gatlinburg, TN, USAEC December 5-7, 1962.

16. J. Hardy, Jr., J. J. Volpe and D. Klejng "Meaşurement and Analysis of Parameters in Tight $232 \mathrm{Th}-235 \mathrm{U}$ and ${ }^{232} \mathrm{Th}$ - $233 \mathrm{U}$ Lattices Moderated With Heavy Watery," NSE, 55, 4011974.

17. D. R. Vondy, Development of a General Method of Explicit Solution to the Nuclide Cha in Equations for Digital Machine Calculations, ORNL-TM-361, 1963.

18. W. W. Engle, Jr., A Users Manual for ANISN, K1693, Oak Ridge National Laboratory, AEC Contract 07405 Eng. 26.

19. Storm-Isreal Evaluated Photon Interaction Library, DLC-15, RSIC Data Library Collection, Oak Ridge, TN.

20. J. R. Knight and F. R. Mynat, MUG: A Program for Generating Multigroup Photon Cross-Sections, CTC-17, RSIC, Oak Ridge National Laboratory, Oak Ridge, TN, January 1970.

21. J. R. Lilley, "Computer Code HFN - Multigroup, Multiregion Neutron Diffusion Theory in One Space Dimension," HW-71545, General Electric Co., 1961 .

22. C. R. Richey, "EGGNIT: A Multigroup Cross-Section Code," BNWL-1203, Battelle-Northwest, Rich7and, Washington, November 1969.

23. C. L. Bennett and W. L. Purcel1, "BRT-1: Battelle-Revised THERMOS," BNWL-1434, Battelle Pacific Northwest Laboratories 1970.

24. BNW/B-IV, Report BNL-17541 (ENDF-201), edited by D. Garber, available from the National Nuclear Data Center, Brookhaven National Laboratory, Upton, NY October 1975.

25. J. J. U110, J. Hardy, Jr., and N. M. Steen, "Review of Thorium 233 U Cycle Thermal Reactor Benchmark Studies," Proc. Thermal Reactor Data Seminar, Brookhaven National Laboratory, May 1968.

26. Code of Federal Regulations, Title 49, Part 178.104.

27. Code of Federal Regulations, Title 49, Part 173.393J. 


\section{DISTRIBUTION}

No. of

Copies

OFFSITE

A. A. Chumm

DOE Patent Division

9800 S. Cass Avenue

Argonne

Argonne National Laboratory

9700 South Cass Avenue

Argonne, IL 60439

Attn: Martin J. Ste ind ler

Oak Ridge National Laboratory

P.0. Box X

Oak Ridge, TN 37830

Attn: A. L. Lotts

Savannah River Laboratory

E. I. duPont de Nemours \& Comp any

Attn: J. D. Spencer

Sandia Laboratory

Albuquerque, NM 87185

Attn: A. Camp

2 Bett is Atomic Power Laboratory Westinghouse Electric Corp.

P.0. Box 79

West Mifflin, PA 15122

Attn: W. A. Weinreich

K. E. Richardson

Los Alamos Scientific Laboratory

P.0. Box 1663

Los Alamos, NM 37545

Attn: G. R. Keepin

Knolls Atomic Power Laboratory

P.0. Box 1072

Schenectady, NY 12301

Attn: D. J. Groetch
No. of

Copies

Babcock \& Wi lcox

P.0. Box 1260

Lynchburg, VA 24505

Attn: C. Youe11

Genera 1 Electric Company

175 Curtner Avenue

San Jose, CA 95125

Attn: P. Miller

West inghouse NFD

West inghouse Electric Company

P.0. Box 355

Pittsburg, PA 15230

Attn: C. Palmer

Electric Power Research

Institute

3412 Hillview Avenue

P.0. Box 10412

Palo Alto, CA 94304

Attn: E. Zebrosk $i$

Genera 1 Atomic Company

P.0. Box 81608

San Diego, CA 92138

Attn: W. V. Goedde 1

Fluor Engineers \& Constructors, Inc.

3333 Michelson Drive

Irvine, CA 92730

Attn: E. W. Neben

2 U.S. Department of Energy $\mathrm{HQ} / F C D$

Washington, DC 20545

Attn: W. W. Ballard

U.S. Department of Energy HQ/OSS

Washington, DC 20545

Attn: S. McDowe 11 
No. of

Copies

2 U.S. Department of Energy HQ/DNR

Washington, DC 20545

Attn: P. R. Clark

R. H. Steele

U.S. Department of Energy Washington, DC 20545

Attn: D. E. Bailey

U.S. Department of Energy

Savannah River Operations Office

P.0. Box A

Aiken, SC 29801

Attn: W. M. Shaffer III

U.S. Department of Energy Oak Ridge Operations Office P.0. Box E

Oak Ridge, TN 37830

Attn: S. W. Ahrends

U.S. Department of Energy

Chicago Operations Office

9800 South Cass Avenue

Chicago, IL 60439

Attn: A. Mravca

27 DOE Technical Information Center

Gas Cooled Reactor Assnciates

3344 N. Torrey Pines Ct.

Suite 300

La Jolla, CA 92037

Attn: K. L. Highfill

\section{EXXON - ONSITE}

Exxon Nuc lear Company, Inc.

2101 Horn Rapids Road

Richland, WA 99352

Attn: 0 . Kruger
No. of

Copies

ONSITE - HEDL

W. E. Roake

E. A. Evans

ONSITE - DOE Richland Operations Office
P. A. Craig
H. E. Ransom
J. J. Keating

ONSITE - Pacific Northwest Laboratory

S. R. Bierman

C. L. Brown

E. D. Clayton

B. M. Durst

S. Goldsmith

B. F. Gore (6)

A. J. Haverfield

R. A. Libby

R. C. Loyd

J. P. McNeese

D. F. Newman

D. E. Olesen

L. D. Will1iams

M. G. Zimmerman

Publishing Coordination (2)

Technical Information (5) 